\title{
Study of Explosive Welding of A6061/sus821/1 Using Interlayers With Different Thicknesses and the Air Shockwave Between Plates
}

\section{Xiang Chen}

Jianghan University

\section{Xiaojie Li}

Dalian University of Technology

\section{Daisuke Inao}

Kumamoto University

\section{Shigeru Tanaka}

Kumamoto University

Kazuyuki hokamoto ( $\nabla$ hokamoto@mech.kumamoto-u.ac.jp )

Institute of Industrial Nanomaterials https://orcid.org/0000-0002-1656-9379

\section{Research Article}

Keywords: Interlayer explosive welding, A6061/SUS821L1, Weldability window, Air shock wave, Interlayer, $\mathrm{SPH}$

Posted Date: May 4th, 2021

DOI: https://doi.org/10.21203/rs.3.rs-448967/v1

License: (1) This work is licensed under a Creative Commons Attribution 4.0 International License. Read Full License

Version of Record: A version of this preprint was published at The International Journal of Advanced Manufacturing Technology on July 23rd, 2021. See the published version at https://doi.org/10.1007/s00170-021-07755-3. 


\title{
Study of explosive welding of A6061/SUS821L1 using interlayers with different thicknesses and the air shockwave between plates
}

\author{
Xiang Chen ${ }^{1,2}$, Xiaojie Li ${ }^{3}$, Daisuke Inao ${ }^{4}$, Shigeru Tanaka ${ }^{2}$, Kazuyuki Hokamoto ${ }^{2, *}$ \\ 1. Hubei Province Key Laboratory of Engineering Blasting, Jianghan University, 430056, \\ People's Republic of China
}

2. Institute of Industrial Nanomaterials, Kumamoto University, 860-8555, Japan

3. State Key Laboratory of Structural Analysis for Industrial Equipment and Department of Engineering Mechanics, Dalian University of Technology, 116024, People’s Republic of China 4. Faculty of Engineering, Kumamoto University, 860-8555, Japan

*Corresponding authors: Kazuyuki Hokamoto

E-mail address: hokamoto@mech.kumamoto-u.ac.jp

\begin{abstract}
:
In this work, interlayers with different thickness were used to weld A6061 aluminum alloy and SUS 821L1 duplex stainless steel. The results indicated that the interlayer thickness had a significant effect on the welding. The influence of the air shock wave between the plates on the welding results was examined. The fluid-Solid coupling finite element method was used to simulate the movement of the interlayer under the action of the air shock wave. The smoothed particle hydrodynamics method was used to simulate the oblique impact process of the plates, and the unwelded samples were analyzed using the simulation results. In the analysis of weldability window, the influence of the interlayer on the upper and lower limits was examined.
\end{abstract}

Keywords: Interlayer explosive welding; A6061/SUS821L1; Weldability window; Air shock wave; Interlayer; SPH 


\section{Introduction}

The joints between high-hardness aluminum alloy and stainless steel have attracted intense research interest in order to produce multi-material structures for functionalization and weight saving ${ }^{1}$. Currently, the main welding methods of high hardness aluminum alloy and stainless steel are friction stirring ${ }^{2}$, TIG welding ${ }^{3}$ and brazing ${ }^{4}$. These methods have limitations in practical application; for example, friction stirring limits the size of the material, while TIG welding and brazing inevitably generate an intermetallic compound (IMC) layer that is known to decrease the bonding strength ${ }^{1}$.

Explosive welding is a face-to-face welding technology that can effectively control the thickness of IMC layer ${ }^{5-7}$. However, in the welding of high-hardness aluminum alloy and stainless steel a thick IMC layer appears at the interface, often leading to welding failure ${ }^{8}$. In a previous study, an interlayer was set between the flyer plate and base plate in explosive welding of high-hardness aluminum alloy and stainless steel ${ }^{9}$ and good welding results were obtained. Nevertheless, a 2.5-5 $\mu \mathrm{m}$ IMC layer was still present at the interface ${ }^{9}$.

In this work, to obtain a thin IMC layer at the interface, A6061 high-hardness aluminum alloy and SUS 821L1 duplex stainless steel were welded using different thin interlayers. The air shockwave between the plates was studied by theoretical analysis and simulations. The welding collision process of the plates was studied using smoothed particle hydrodynamics (SPH) simulations and the effect of the interlayer thickness on 
the weldability window was examined.

\section{Materials and methods}

$3 \mathrm{~mm}$-thick JIS A6061 was used as the fly plate, and $3 \mathrm{~mm}$-thick JIS SUS 821L1 was

used as the base plate ${ }^{10} .0 .5 \mathrm{~mm}$-thick, $0.3 \mathrm{~mm}$-thick and $0.1 \mathrm{~mm}$-thick JIS SUS 304 were used as the interlayer.

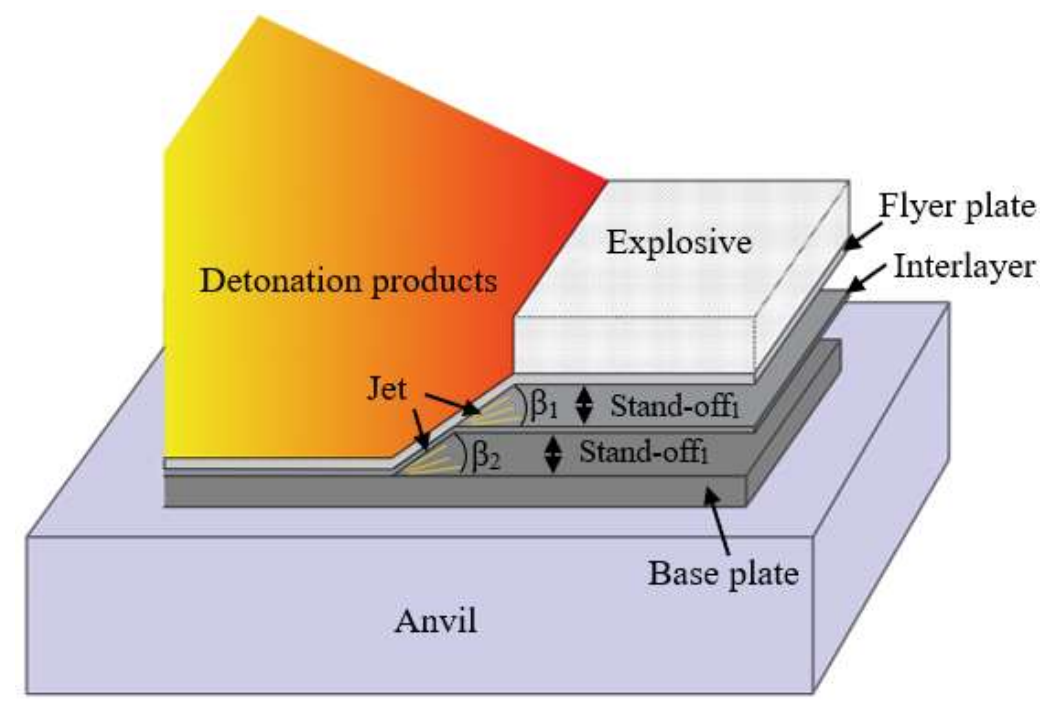

Fig. 1 Schematic of explosive welding with an interlayer.

Table 1 Experimental parameters and results.

\begin{tabular}{ccccccc}
\hline Samples & $\begin{array}{c}\text { Thickness of } \\
\text { explosive } \\
(\mathrm{mm})\end{array}$ & $\begin{array}{c}\text { Detonation } \\
\text { velocity } D \\
(\mathrm{~m} / \mathrm{s})\end{array}$ & $\begin{array}{c}\text { Stand-off } \\
(\mathrm{mm})\end{array}$ & $\begin{array}{c}\text { Stand-off } \\
(\mathrm{mm})\end{array}$ & Interlayer & $\begin{array}{c}\text { Welding } \\
\text { results }\end{array}$ \\
\hline 1 & 38 & 2450 & 2 & $/$ & $/$ & Unwelded \\
2 & 48 & 2575 & 2 & 2 & $0.5 \mathrm{~mm}$-SUS 304 & Welded \\
3 & 48 & 2575 & 2 & 2 & $0.3 \mathrm{~mm}$-SUS 304 & Welded \\
4 & 48 & 2575 & 2 & 2 & $0.1 \mathrm{~mm}$-SUS 304 & Unwelded \\
5 & 28 & 2350 & 2 & 2 & $0.1 \mathrm{~mm}$-SUS 304 & Unwelded \\
\hline
\end{tabular}

Flyer plate velocity $\left(V_{\mathrm{P}}\right)$ and the collision angle $(\beta)$ are important factors for the calculation of the welding parameters of explosives. The relationship can be 
expressed using the following equation ${ }^{11}$ :

$$
V_{\mathrm{P}}=
$$

$2 V_{\mathrm{D}} \sin \frac{\beta}{2}$

where $V_{\mathrm{D}}$ is the detonation velocity of the explosive. The collision angle $\beta$ can be calculated using the following equation ${ }^{12}$ :

$$
\begin{aligned}
& =\left(\sqrt{\frac{K+1}{K-1}}\right. \\
& -1) \frac{\pi}{2} \frac{r}{r+2.71+\frac{0.184 t_{\mathrm{e}}}{s}}
\end{aligned}
$$

where $r$ is the loading ratio (mass of explosive per unit mass of flyer plate), $t_{\mathrm{e}}$ and $s$ are the explosive thickness and the stand-off distance, respectively, and $K$ is the gaseous polytropic index of the detonation products.

The energy dissipated at the interface during the collision has an important effect on the results of explosive welding. In direct explosive welding, the kinetic energy loss $(\triangle K E)$ during the collision can be obtained using the following equation ${ }^{13}$ :

$=\frac{\left(m_{\mathrm{D}} m_{\mathrm{C}} V_{\mathrm{P}}^{2}\right)}{2\left(m_{\mathrm{D}}+m_{\mathrm{C}}\right)}$

where $m_{\mathrm{C}}$ is the mass per unit area of the collided plate, and $m_{\mathrm{D}}$ is the mass per unit area of the flyer plate. The calculated results are presented in Table 4. References ${ }^{14}$ and ${ }^{13}$ give the values of the $K$ and $V_{\mathrm{D}}$ parameters listed in Table 5. $\Delta K E_{1}$ is the kinetic energy loss between the flyer plate and the interlayer. 
Table 2 Calculated $V_{\mathrm{P}}, \beta$ and $\Delta \mathrm{KE}$.

\begin{tabular}{cccccccc}
\hline Sample & $K$ & $\begin{array}{c}\text { Explosive } \\
\text { Ratio } r\end{array}$ & $\begin{array}{r}\text { Velocity of } \\
\text { flying plate } \\
V_{\text {Pmin }}(\mathrm{m} / \mathrm{s})\end{array}$ & $\begin{array}{c}\text { Velocity of } \\
\text { flying plate } \\
V_{\operatorname{Pmax}}(\mathrm{m} / \mathrm{s})\end{array}$ & $\begin{array}{c}\text { Collision } \\
\text { angle } \beta_{\min }\end{array}$ & $\begin{array}{c}\text { Collision } \\
\text { angle } \beta_{\max }\end{array}$ & $\begin{array}{c}\Delta K E_{1} \\
\left(\mathrm{KJ} / \mathrm{m}^{2}\right)\end{array}$ \\
\hline 1 & 2.37 & 1.49 & 423 & $/$ & $9.9^{\circ}$ & $/$ & 1176 \\
2 & 2.48 & 1.88 & 450 & 596 & $10.0^{\circ}$ & $13.3^{\circ}$ & 310 \\
3 & 2.48 & 1.88 & 450 & 596 & $10.0^{\circ}$ & $13.3^{\circ}$ & 205 \\
4 & 2.48 & 1.88 & 450 & 596 & $10.0^{\circ}$ & $13.3^{\circ}$ & 76 \\
5 & 2.20 & 1.10 & 402 & 502 & $9.8^{\circ}$ & $12.3^{\circ}$ & 60 \\
\hline
\end{tabular}

\section{Results and discussions}

\subsection{Microstructure of the interface}

Fig. 2 shows the images of the microstructures of the samples obtained using different welding conditions. It is observed that Samples 1, 4 and 5 were not welded. For Sample 1, this may be due to the excessive energy deposition at the interface, while for Samples 4 and 5 this may be due to the low energy deposition at the interface. Below, we will analyze the origin for the lack of welding of Samples 1,4 and 5 by combining simulation results and the weldability window. Comparison of Samples 2 and 3 clearly showed that a thinner interlayer led to the lesser formation of melting. The interface between the aluminum alloy and interlayer was flat, indicating that the welding parameters were at the left side of the weldability window's left limit. The interface between the interlayer and base plate of Sample 4 is wavy, while that of Sample 5 is flat, implying that the weldability window's left limit for SUS 304 and SUS $821 \mathrm{~L} 1$ is between $2350 \mathrm{~m} / \mathrm{s}$ and $2575 \mathrm{~m} / \mathrm{s}$. 

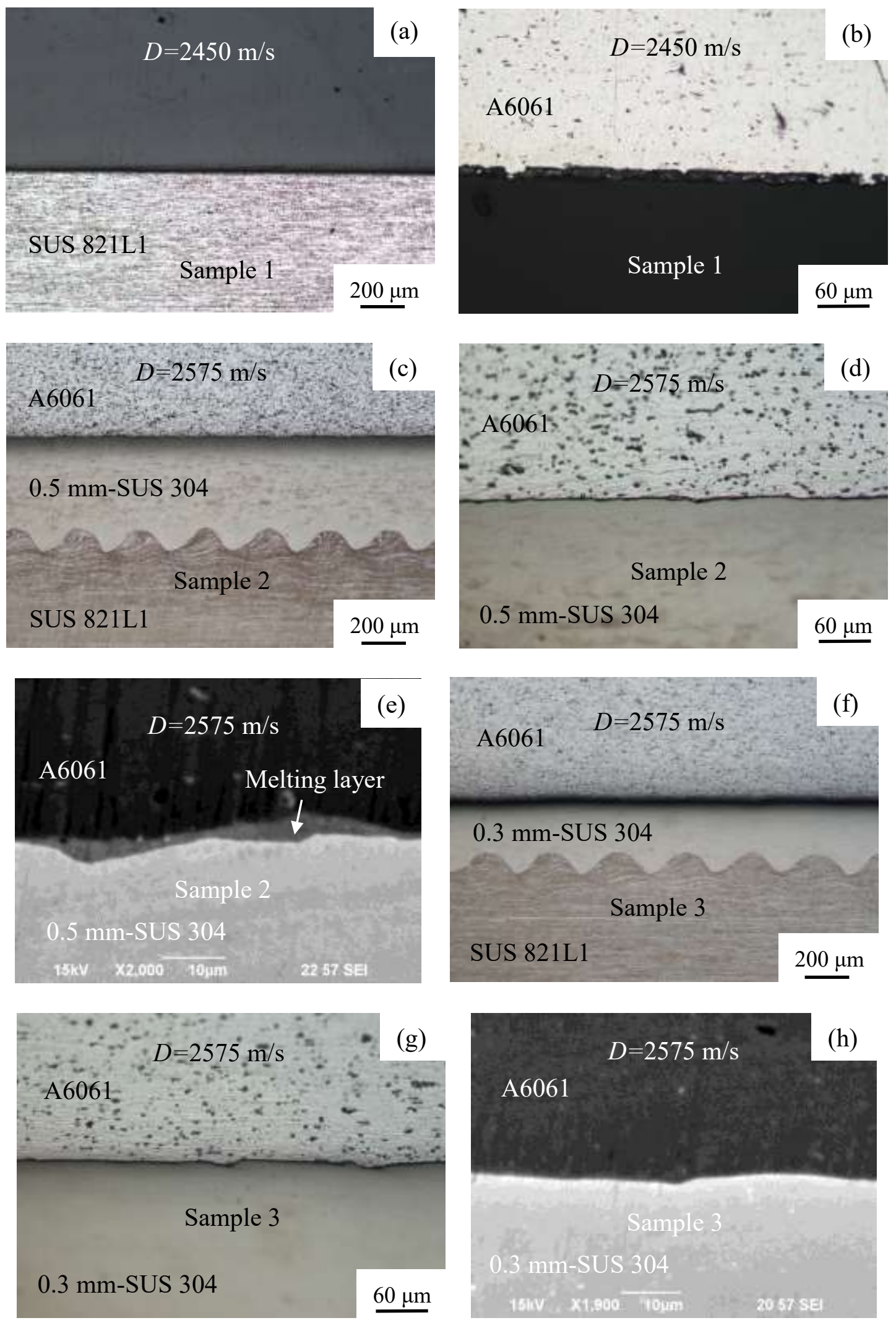

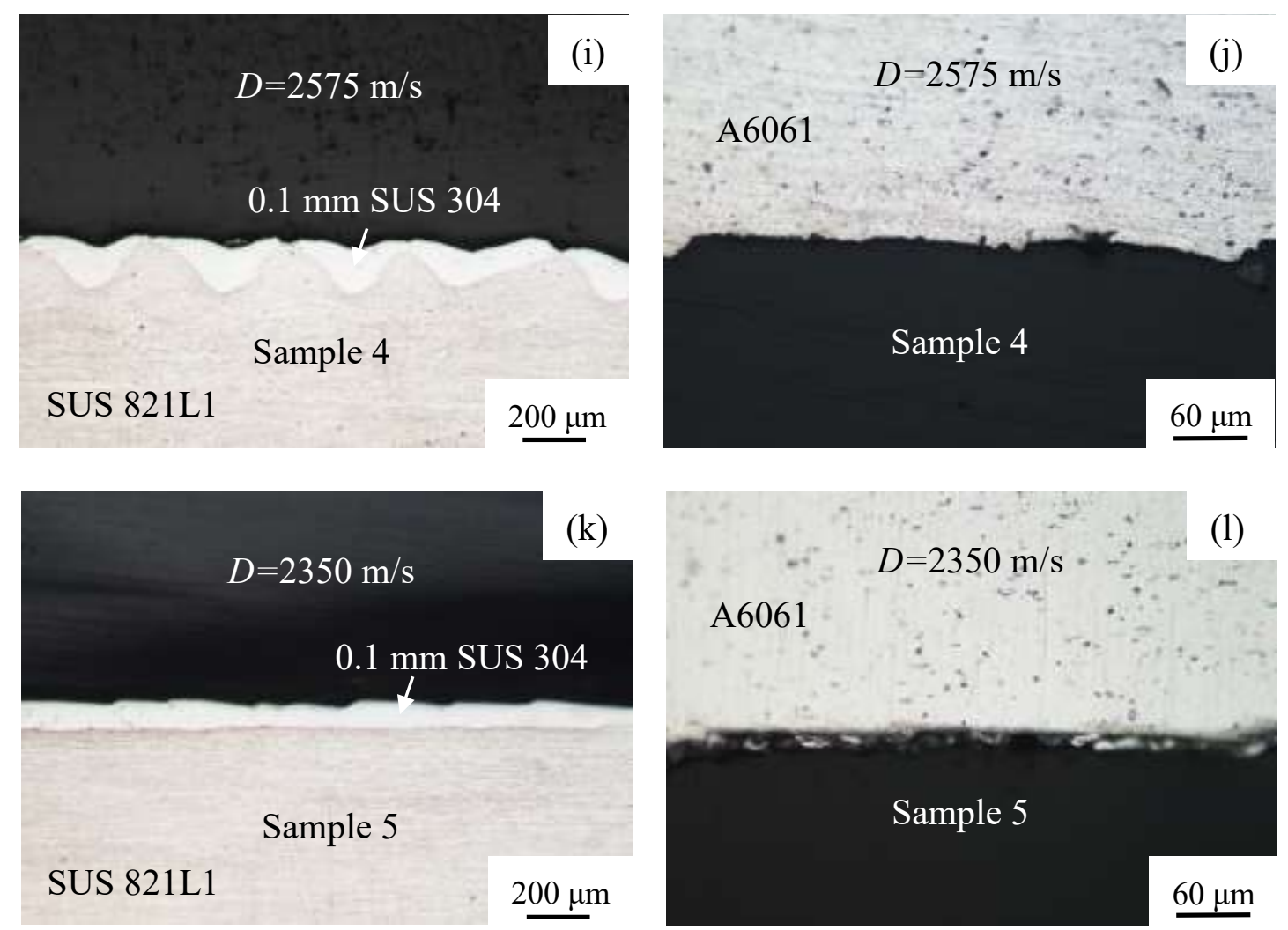

Fig. 2 Microstructure of the interface: $(\mathrm{a}, \mathrm{b})$ Sample 1; (c, d, e) Sample 2; (f, g, h) Sample 3; (i,

j) Sample 4; (k, l) Sample 5.

\subsection{Mechanical properties}

The samples were processed using the method described in a previous work ${ }^{9}$. To ensure that the axis of the force is on the interface, the aluminum alloy side was machined to a thickness of $3 \mathrm{~mm}$. The measured shear strengths of the two samples were almost the same and the samples differed mainly in regard to the fracture location. As shown in Fig. 3, the fracture of Sample 2 appeared on the A6061 side, indicating that the bonding at the interface was higher than the measured value, while the fracture of Sample 3 appeared at the interface, suggesting that the measured value was the bonding strength of the interface. The relatively low bonding strength of Sample 3 may be due to the almost complete absence of the melting layer at the interface. Although a too thick melting layer is known to have a negative effect on the welding strength, the present experimental results showed that a certain thickness of the melting layer is beneficial for welding strength. 
Table 3 Tensile shear test parameters.

\begin{tabular}{cccccc}
\hline & Actual distance & Loading & Measured & Main location of \\
Sample & $\begin{array}{c}\text { length } \times \text { width } \times \text { height } \\
(\mathrm{mm})\end{array}$ & between cuts & speed & shear strength & fracture \\
& $83.10 \times 9.72 \times 5.80$ & 2.73 & 0.1 & 203.8 & A6061 side \\
\hline 2 & $83.00 \times 10.00 \times 5.80$ & 2.73 & 0.1 & 208.6 & Interface \\
\hline
\end{tabular}
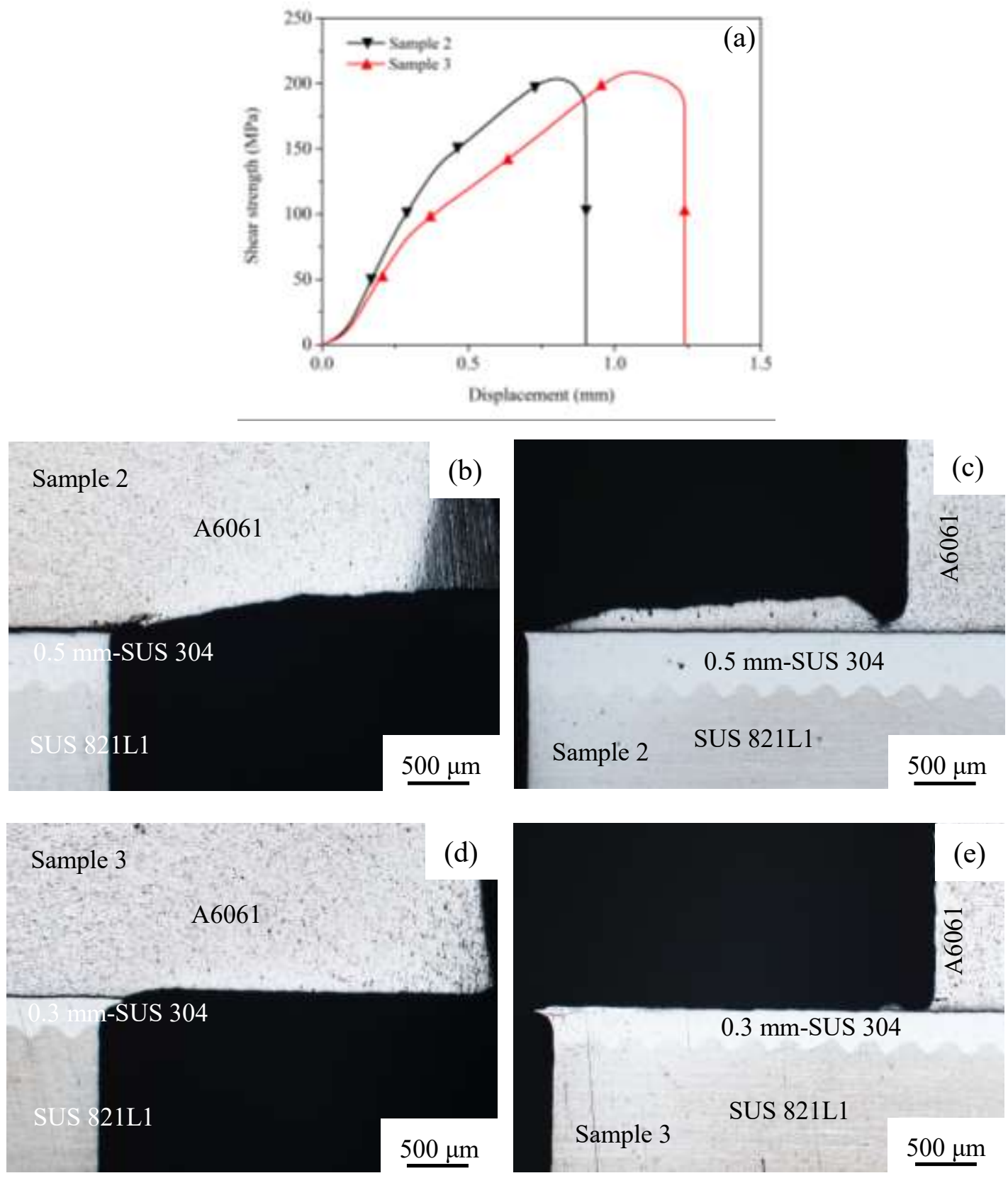

Fig. 3 Tensile shear test: (a) tensile shear curve; (b) and (c) Sample 2; (d) and (e) Sample 3. 


\subsection{The air shock wave between plates}

Explosive welding is usually carried out in air. For the small size plate, the jet will quickly eject out of the gap between the flyer plate and the base plate and will not affect the welding result. However, in the welding of large plates, the air before the collision point was compressed, and the jet combustion also heated the gas in the gap, giving rise to the expansion of the gas and thus leading the flyer plate to move upward and affecting the welding results.

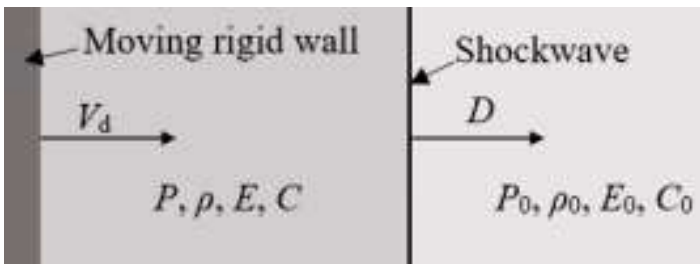

(a)

(b)

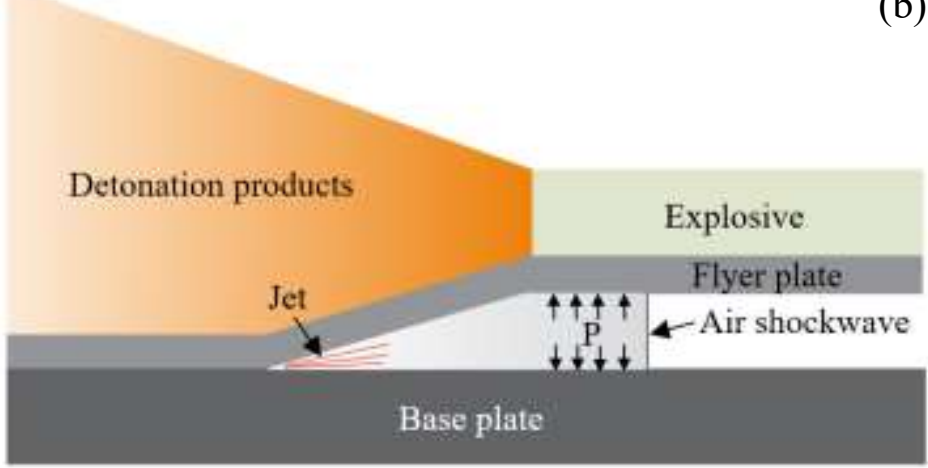

Fig. 4 Schematic of the air shock wave: (a) piston model; (b) schematic of explosive welding.

When the collision point between the flyer plate and the base plate moves from left to right, it acts as a moving "piston" and compresses the gas in the gap, as shown in Fig. 4(a), and its speed is equal to the detonation velocity $V_{\mathrm{d}}$. A gas shockwave will form in the gap. The air shockwave between the flyer plate and interlayer will propagate 
ahead of the detonation wave as shown in Fig. 4(b), so that the flyer plate will be jacked up and the density of the explosive on the flyer plate will change. These phenomena will change the welding parameters, affecting the welding result.

Assuming that the velocity of air shockwave is $D$, the gas in front of the air shockwave is the undisturbed area, the gas velocity is 0 , the pressure is atmospheric pressure $P_{0}$, the gas density is $\rho_{0}$, the internal energy per unit mass is $E_{0}$, the sound velocity is $C_{0}$, and the corresponding parameters after the impact of the shockwave are $V_{\mathrm{d}}, P, \rho, E, C$, then the parameters satisfy the following shockwave relations in the piston model:

$$
\left\{\begin{array}{c}
\rho_{0} D=\rho\left(D-V_{d}\right) \\
P-P_{0}=\rho_{0} D V_{d} \\
E-E_{0}=\frac{1}{2}\left(P+P_{0}\right)\left(\frac{1}{\rho_{0}}-\frac{1}{\rho}\right)
\end{array}\right.
$$

The specific internal energy $E$ and sound velocity $C$ can be obtained by using the polytropic gas equation.

$$
=\sqrt{\frac{\gamma P}{\rho}} \quad \begin{array}{ll}
E=\frac{1}{\gamma-1} \frac{P}{\rho} ; \quad C \\
\end{array}
$$

where $\gamma$ is the adiabatic exponent. In Eq. (4), the parameters for the gas in front of the shockwave are known, and the particle velocity after the shockwave is $V_{\mathrm{d}}$, and the parameters of interest are the shockwave velocity $D$ and shockwave pressure $P$. The $E$ of Eq. (5) is substituted into Eq. (4) to obtain: 


$$
\left\{\begin{array}{c}
\frac{\rho_{0}}{\rho}=1-\frac{V_{d}}{D} \\
P=P_{0}+\rho_{0} D V_{d} \\
\frac{2 \rho_{0}\left(\frac{P}{\rho}-\frac{P_{0}}{\rho_{0}}\right)}{\gamma-1}=\frac{P+P_{0}}{1-\frac{\rho_{0}}{\rho}}
\end{array}\right.
$$

By combining Eqs. (5) and (6), the following one variable quadratic algebraic equation in $D$ can be obtained:

$$
\begin{gathered}
\left(\frac{D}{V_{d}}\right)^{2}-\frac{\gamma+1}{2}\left(\frac{D}{V_{d}}\right)-\left(\frac{C_{0}}{V_{d}}\right)^{2}=0 \\
\left\{\begin{array}{c}
\frac{D}{V_{d}}=\frac{\gamma+1}{4} \pm \sqrt{\frac{(\gamma+1)^{2}}{16}+\left(\frac{C_{0}}{V_{d}}\right)^{2}} \\
P-P_{0}=\rho_{0} D V_{d}
\end{array}\right.
\end{gathered}
$$

The pressure of the gas between the flyer plate and base plate can be obtained by Eq.

(8). The actual situation is much more complex than the above model; for example, the gas does not satisfy the ideal gas hypothesis, and the high temperature and pressure of the shockwave will ionize the gas ${ }^{15-16}$ decreasing the adiabatic exponent, and the shockwave velocity and pressure. However, the jet will enter the high temperature and high pressure air shockwave. The metal particles in the jet react with oxygen, nitrogen and other gases in the air shockwave, changing the gas composition and increasing its internal energy and mass density, thus increasing the shockwave pressure. In addition, the high pressure generated by the shockwave will squeeze and lift the clad plate and explosive, increases the space after the shockwave and decrease the pressure. Considering these factors, it is clear that accurate results cannot be obtained by Eq. (8); nevertheless, the model of Eq. (8) can still roughly reflect the gas 
flow between the flyer plate and base plate. As mentioned above, the air shock phenomenon will be obvious in the welding of large plates. In interlayer welding, the interlayer is usually thin. Under the action of the air shockwaves between the flyer plate and interlayer, and between the interlayer and the base plate, the interlayer will swing, as shown in the schematic of the air shock wave in interlayer shown in Fig. 5(a). The parameters of the air are listed in Table 4. The calculation results using the piston model are shown in Table 5, and it is observed the air shock wave becomes stronger with increasing detonation velocity. The welding parameter of Sample 5 is at the left side of the left limit, and the interface should be flat as shown in Fig. 2(k); however, an irregular interface was obtained as shown in Fig. 5(b), due to the influence of the air shock wave between the plates. For a small plate, the impact is small. Since realistic interlayer explosive welding is different from the piston model, the air shock wave between the plates was studied by numerical simulations.

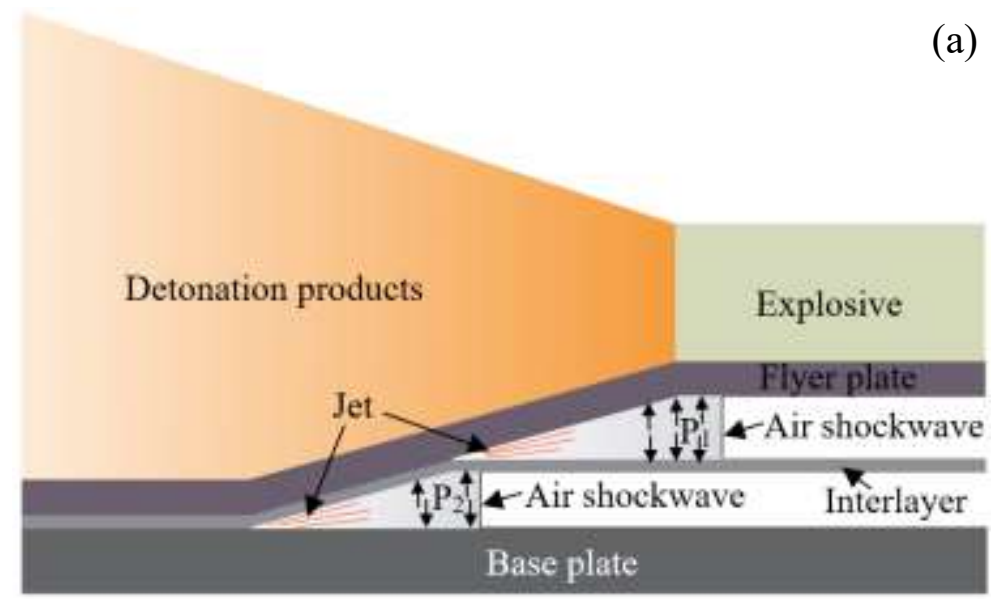




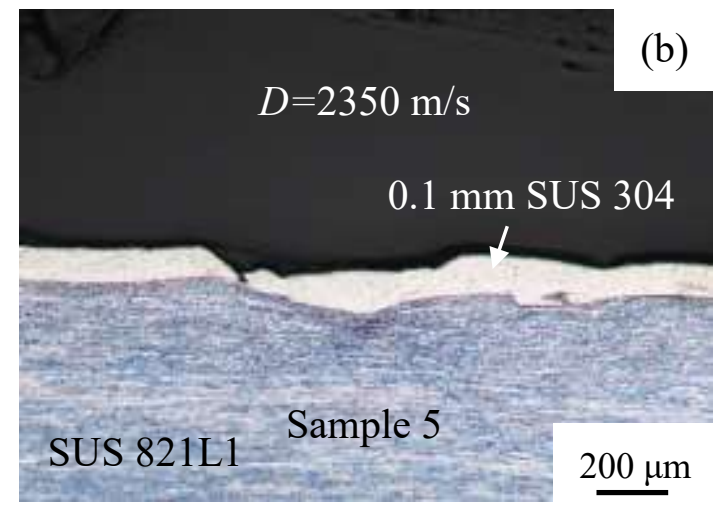

Fig. 5 Schematic of the air shock wave during interlayer explosive welding.

Table 4 Parameters of air.

\begin{tabular}{cccc}
\hline Molecular & Adiabatic & Sound velocity at atmospheric & $\begin{array}{c}\text { Density } \rho \\
\text { weight } M\end{array}$ \\
\hline exponent $\gamma$ & pressure $C_{0}(\mathrm{~m} / \mathrm{s})$ & 1.292 \\
\hline
\end{tabular}

Table 5 Pressure of the air shockwave calculated by the piston model.

\begin{tabular}{cccc}
\hline Sample & Detonation velocity $(\mathrm{m} / \mathrm{s})$ & $\mathrm{D} / V_{\mathrm{d}}$ & Air shockwave $P(\mathrm{MPa})$ \\
\hline 4 & 2575 & 1.216 & 10.417 \\
5 & 2350 & 1.218 & 8.676 \\
\hline
\end{tabular}

\section{Numerical simulations}

\subsection{Simulation of shock wave between plates}

\subsubsection{Piston model}

Fluid-solid coupling finite-element algorithm was used to simulate the piston model. The numerical model is shown in Fig. 6(a), and 9 observation points were set up. Fig. $6(\mathrm{~b})$ indicates that the pressure was uniform in front of the moving rigid wall, and the action time of the shock wave increased according to the distance as shown in Fig. 6(c). The obtained simulated results presented in Table 6 are close to the calculated results presented in Table 5, verifying the accuracy of the numerical simulations. 

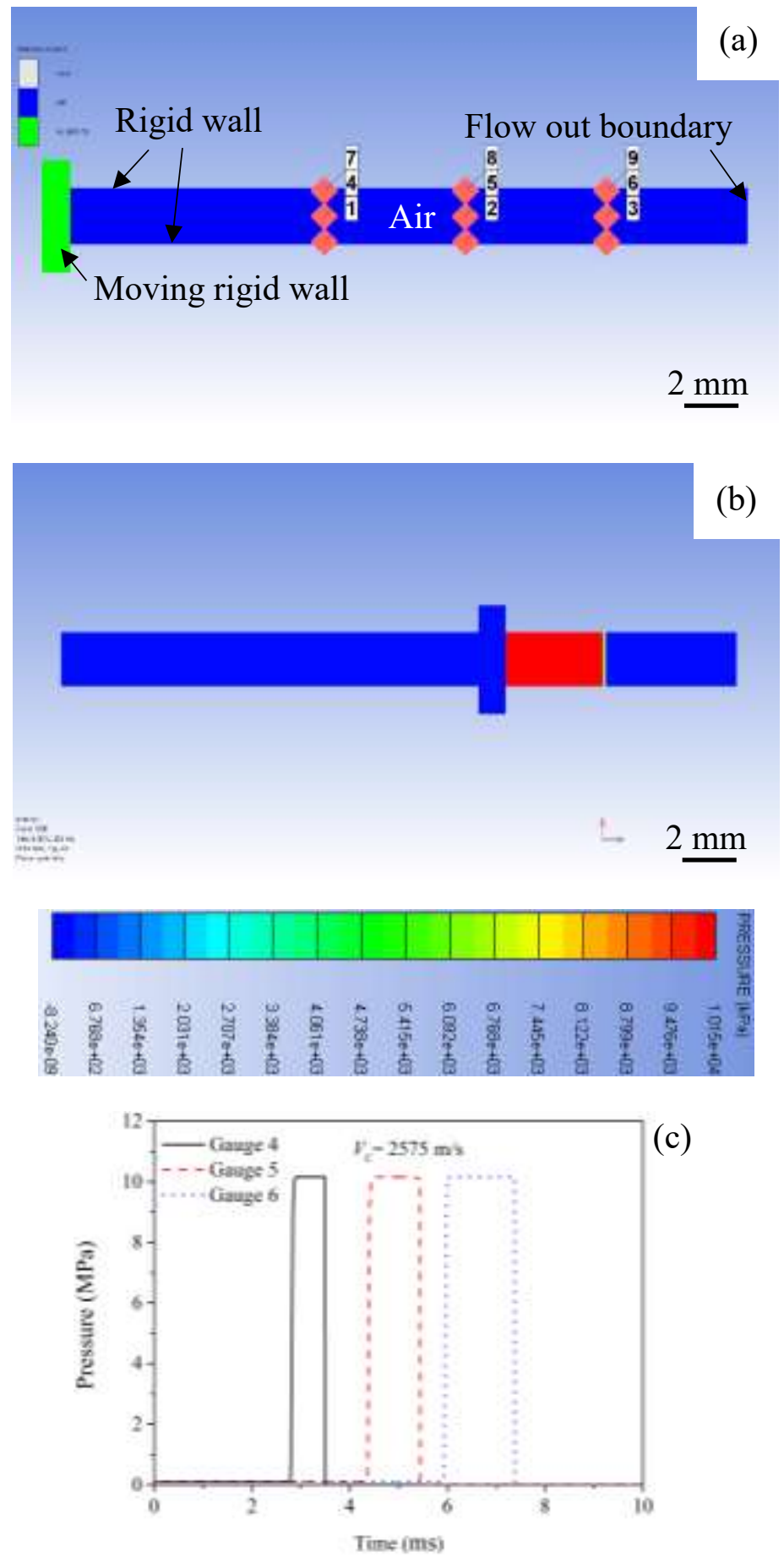

Fig. 6 Simulation of the air shock wave using the piston model: (a) numerical model; (b) pressure distribution; (c) pressure curve of points 4, 5 and 6 of the oblique collision model.

Table 6 Peak pressure of the observation point (Unit: MPa).

Gauge Gauge Gauge Gauge Gauge Gauge Gauge Gauge Gauge

$\begin{array}{lllllllll}1 & 2 & 3 & 4 & 5 & 6 & 7 & 8 & 9\end{array}$

Piston model 


\subsubsection{Interlayer explosive welding}

The parameters used in the simulation are shown in Tables 7 and 8, and the parameters of the ANFO explosive used the modified JWL equation in reference ${ }^{17}$. The numerical model is shown in Fig. 7(b). The pressure between the flyer plate and interlayer was smaller than the pressure between the interlayer and the base plate as shown in Fig. 7(b). Similar to the piston model, the action time of the shock wave was found to increase with the distance as shown in Figs. 7(c) and 7(h). The impulse of the air shock wave in Fig. 7(d) and Fig. 7(i) increases the distance, implying that the impact of the air shock wave will be greater farther away from the initiation point. Figs. 7(e) and 7(j) show that the interlayer had a non-zero velocity under the air shock wave. The displacement caused by the velocity is shown in Figs. 7(f) and 7(k), and it is observed that the displacement of the $0.1 \mathrm{~mm}$-thick interlayer was greater than that of the $0.8 \mathrm{~mm}$-thick interlayer. The displacement of the interlayer will change the stand-off and this may be the origin of the uneven interface observed in Fig. 5(b). Figs. 7(g) and 7(l) indicated that the air shock wave caused the plastic deformation of the plate. The pressure distribution of the air shock wave is shown in Figs. 7(m) and $7(\mathrm{n})$, and it is observed that with the increase in the propagation distance of the air shock wave, the distance $S$ between the two air shock waves decreased due to the interlayer movement downward under the action of the air shock wave between the flyer plate and the interlayer. This movement expanded the space between the flyer plate and interlayer, and weakened the shock wave between the flyer plate and the interlayer. At the same time, the movement reduced the space between the interlayer and the base plate and strengthened the shock wave between the interlayer and the base plate. If the length of the plate is large enough, the shock wave between the interlayer and the base plate will catch up with the shock wave between the flyer plate and the interlayer. In this case, the interlayer will move upward, the shock wave 
between interlayer and base plate will be weakened, and the shock wave between the flyer plate and the interlayer will be strengthened, causing the whole interlayer to swing up and down. The simulation results show that the effect of the air shock wave is more pronounced for thinner interlayers.

Table 7 Parameters of the shock equation of state ${ }^{18}$.

\begin{tabular}{cccccc}
\hline Materials & $\begin{array}{c}\text { Gruneisen } \\
\text { Coefficient } \gamma\end{array}$ & $\begin{array}{c}\text { Parameter } C_{1} \\
(\mathrm{~m} / \mathrm{s})\end{array}$ & Parameter $S_{1}$ & $\begin{array}{c}\text { Reference } \\
\text { Temperature }(\mathrm{K})\end{array}$ & $\begin{array}{c}\text { Specific Heat } \\
\left(\mathrm{J} \cdot \mathrm{kg}^{-1} \cdot \mathrm{K}^{-1}\right)\end{array}$ \\
\hline A6061 & 1.97 & 5240 & 1.40 & 300 & 885 \\
SUS 821L1 & 2.17 & 4569 & 1.49 & 300 & 452 \\
SUS 304 & 2.17 & 4569 & 1.49 & 300 & 452 \\
Steel 1006 & 2.17 & 4569 & 1.49 & 300 & 452 \\
\hline
\end{tabular}

Table 8 Johnson-Cook's law parameters ${ }^{19-20}$.

\begin{tabular}{ccccccc}
\hline & $A(\mathrm{MPa})$ & $B(\mathrm{MPa})$ & $C$ & $n$ & $m$ & $T_{\mathrm{m}}$ \\
\hline A6061 & 324 & 114 & 0.002 & 0.42 & 1.34 & $855 \mathrm{~K}$ \\
SUS 821L1 & 577 & 1100 & 0.015 & 0.50 & 0.70 & $1811 \mathrm{~K}$ \\
SUS 304 & 280 & 1100 & 0.015 & 0.50 & 0.70 & $1811 \mathrm{~K}$ \\
STEEL 1006 & 350 & 275 & 0.022 & 0.36 & 1.00 & $1811 \mathrm{~K}$ \\
\hline
\end{tabular}

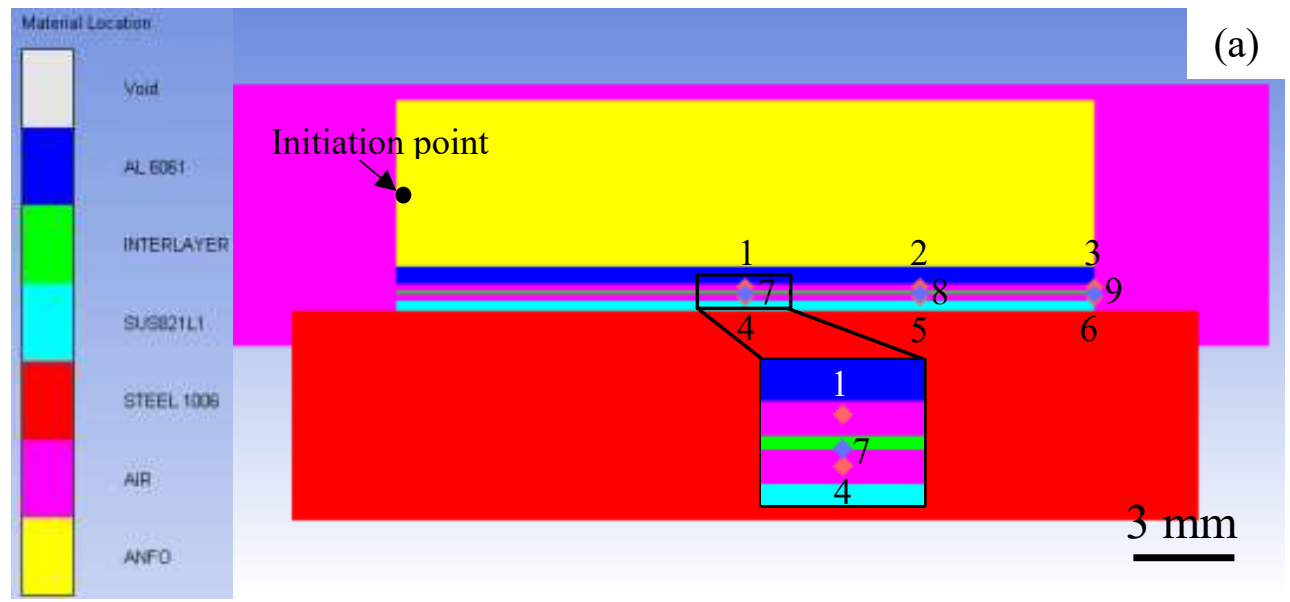



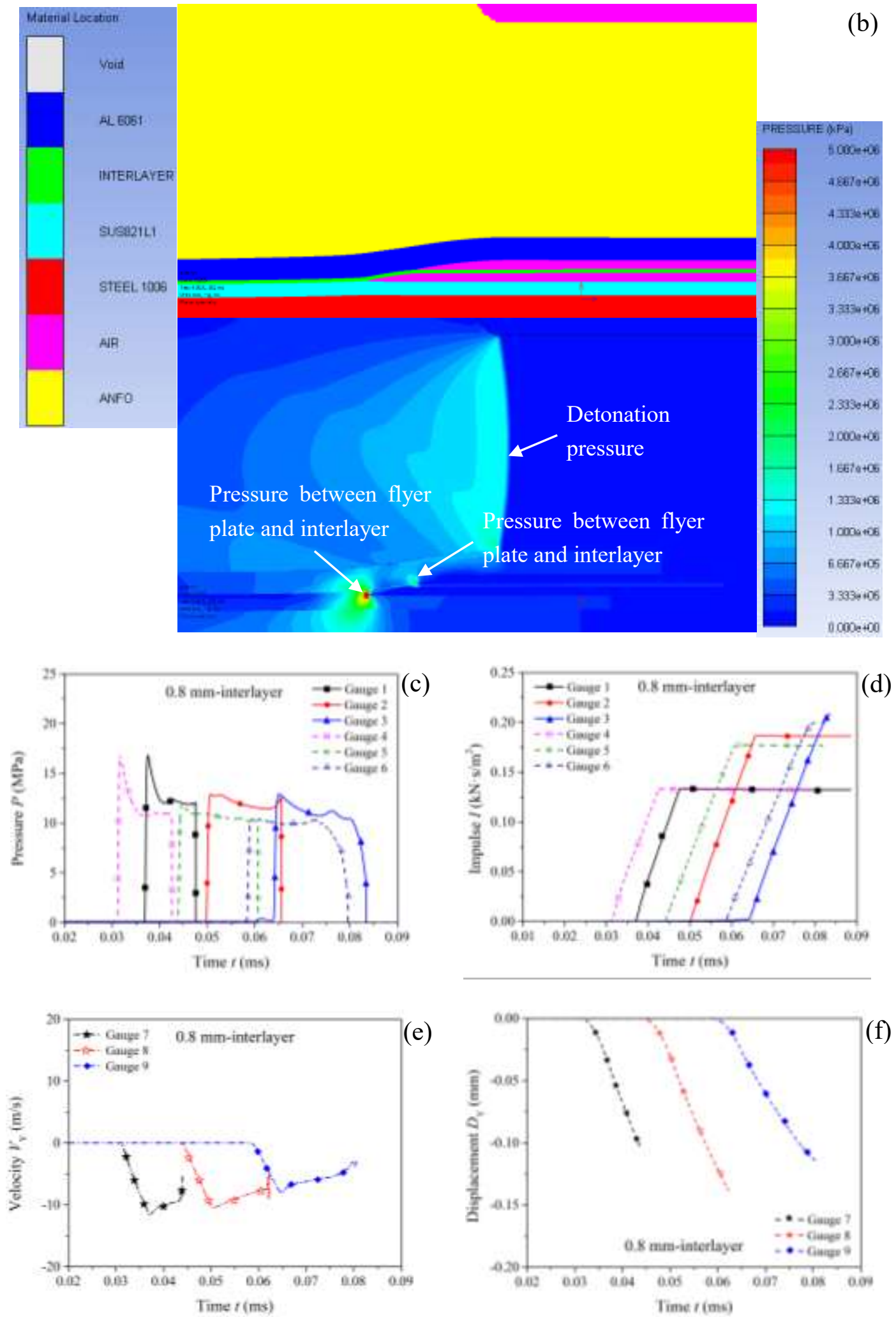

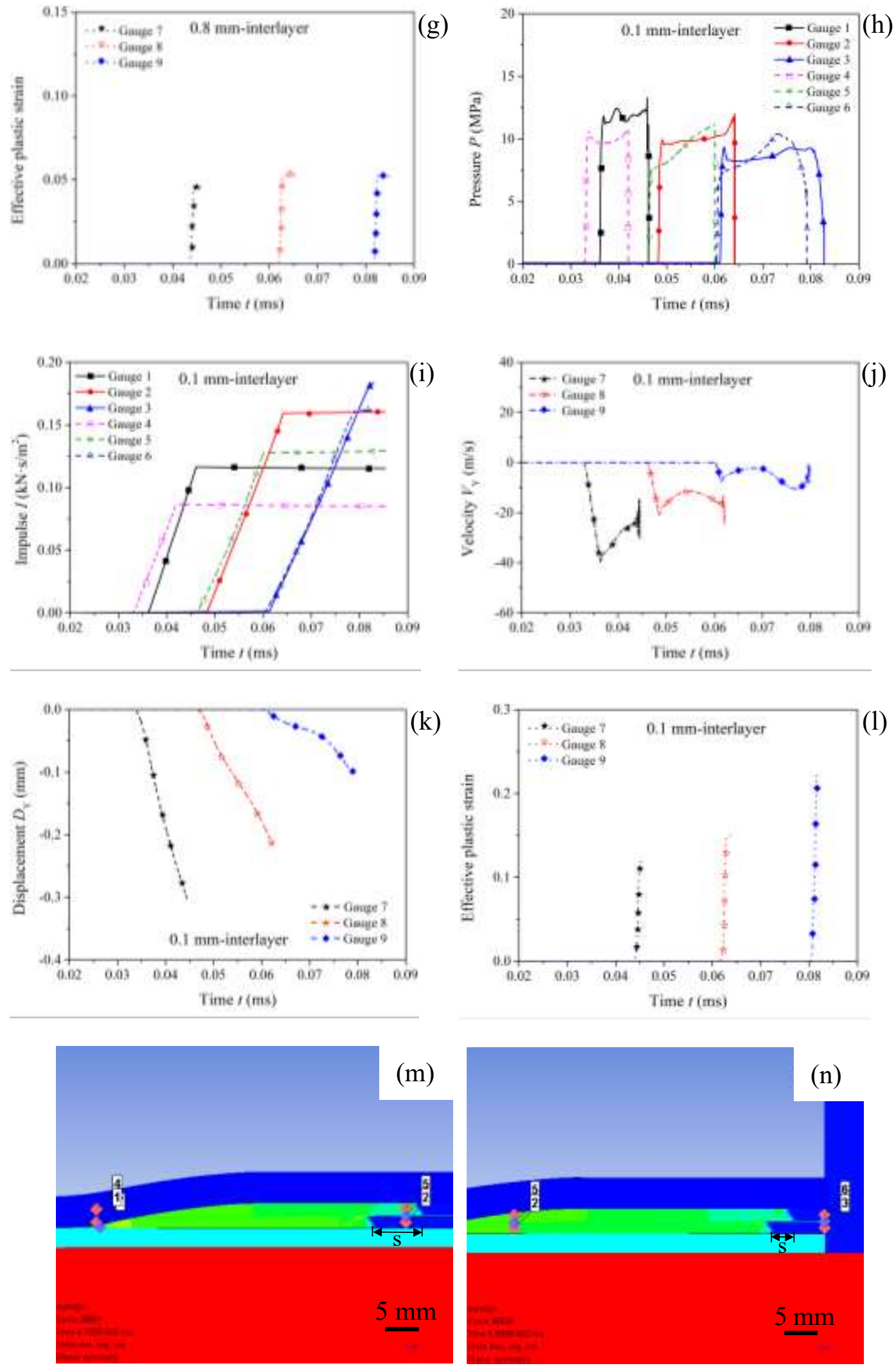

Fig. 7 Simulation of the air shock wave between the plates: (a) numerical model; (b) pressure distribution of the $0.8 \mathrm{~mm}$-thick interlayer explosive welding; $(\mathrm{c}, \mathrm{h})$ pressure of the air shock 
wave; (d, i) impulse of the air shock wave (e, j) interlayer's velocity under the air shock wave; (f, k) interlayer's displacement under air shock; $(g, 1)$ effective plastic strain under the air shock wave; $(\mathrm{m}, \mathrm{n})$ pressure distribution of the $0.1 \mathrm{~mm}$-thick interlayer.

\subsection{Simulation of collision process}

The SPH numerical method is suitable for simulating large deformations and has been extensively used for the simulations of explosive welding processes. In particular, the simulations of the explosive welding process have been performed using the inclined collision of plates at a given flyer plate velocity $V_{\mathrm{P}}$ and collision angle $\beta^{21-22}$. Here, the interface between the flyer plate and interlayer was welded when the flyer plate just collided with the interlayer, the simulation of the interface used the parameters calculated by Eqs. (1) and Eq. (2), and the stand-off 1 between flyer plate and interlayer was used in the calculation.

In the simulation of the interface between the interlayer and the base plate, the interlayer was neglected in the calculation of the collision velocity and collision angle, and the stand-off $1+$ stand-off $_{2}$ between the flyer plate and the base plate was used in the calculation.

The calculated parameters under the two conditions are shown in Table 9. The parameters in 1, 2-1, 3-1, 4-1, 5-1 were used in the simulation of the flyer plate and the interlayer, and the parameters in 2-2,3-2, 4-2, 5-2 were used in the simulation of the interlayer and the base plate. The simulated collision angle between the interlayer and the base plate are shown in Table 10.

The Von Mises stress was used to evaluate the melting ${ }^{23}$. The simulated results presented in Fig. 8 show that the jet was propagating only from the A6061 side. The jet and melting were reduced with decreasing thickness of the collided plate. No jet or melting was observed when using the $0.1 \mathrm{~mm}$-thick interlayer. The simulation results indicated that Sample 1 was not welded due to the high-energy deposition at the interface, and the excessive melting led to the welding failure. Samples 4 and 5 were not welded due to the low energy deposition at the interface, and no jet and melting 
appeared at the interface of Samples 4 and 5. The wave between the interface and the base plate increased with decreasing thickness of the interlayer. The jet in Fig. 8(m) may penetrate the interlayer, and then form the irregular interface as shown in Fig. 8(o).

Table 9 Relationship between the flyer plate velocity and collision angle.

\begin{tabular}{cccc}
\hline Conditions & Stand-off & $\begin{array}{c}\text { Collision } \\
\text { angle } \beta\end{array}$ & $\begin{array}{c}\text { Flyer plate } \\
\text { velocity } V_{\mathrm{P}}(\mathrm{m} / \mathrm{s})\end{array}$ \\
\hline 1 & 2 & $9.9^{\circ}$ & 423 \\
$2-1$ & 2 & $10^{\circ}$ & 450 \\
$2-2$ & 4 & $13.3^{\circ}$ & 596 \\
$3-1$ & 2 & $10^{\circ}$ & 450 \\
$3-2$ & 4 & $13.3^{\circ}$ & 596 \\
$4-1$ & 2 & $10^{\circ}$ & 450 \\
$4-2$ & 4 & $13.3^{\circ}$ & 596 \\
$5-1$ & 2 & $9.8^{\circ}$ & 402 \\
$5-2$ & 4 & $12.3^{\circ}$ & 502 \\
\hline
\end{tabular}

Table 10 Collision angle between the interlayer and the base plate.

\begin{tabular}{ccc}
\hline Samples & Collision angle $\beta_{2 \min }$ & Collision angle $\beta_{2 \max }$ \\
\hline 2 & $8.0^{\circ}$ & $11.7^{\circ}$ \\
3 & $9.6^{\circ}$ & $12.0^{\circ}$ \\
4 & $9.8^{\circ}$ & $12.9^{\circ}$ \\
5 & $9.5^{\circ}$ & $11.7^{\circ}$ \\
\hline
\end{tabular}



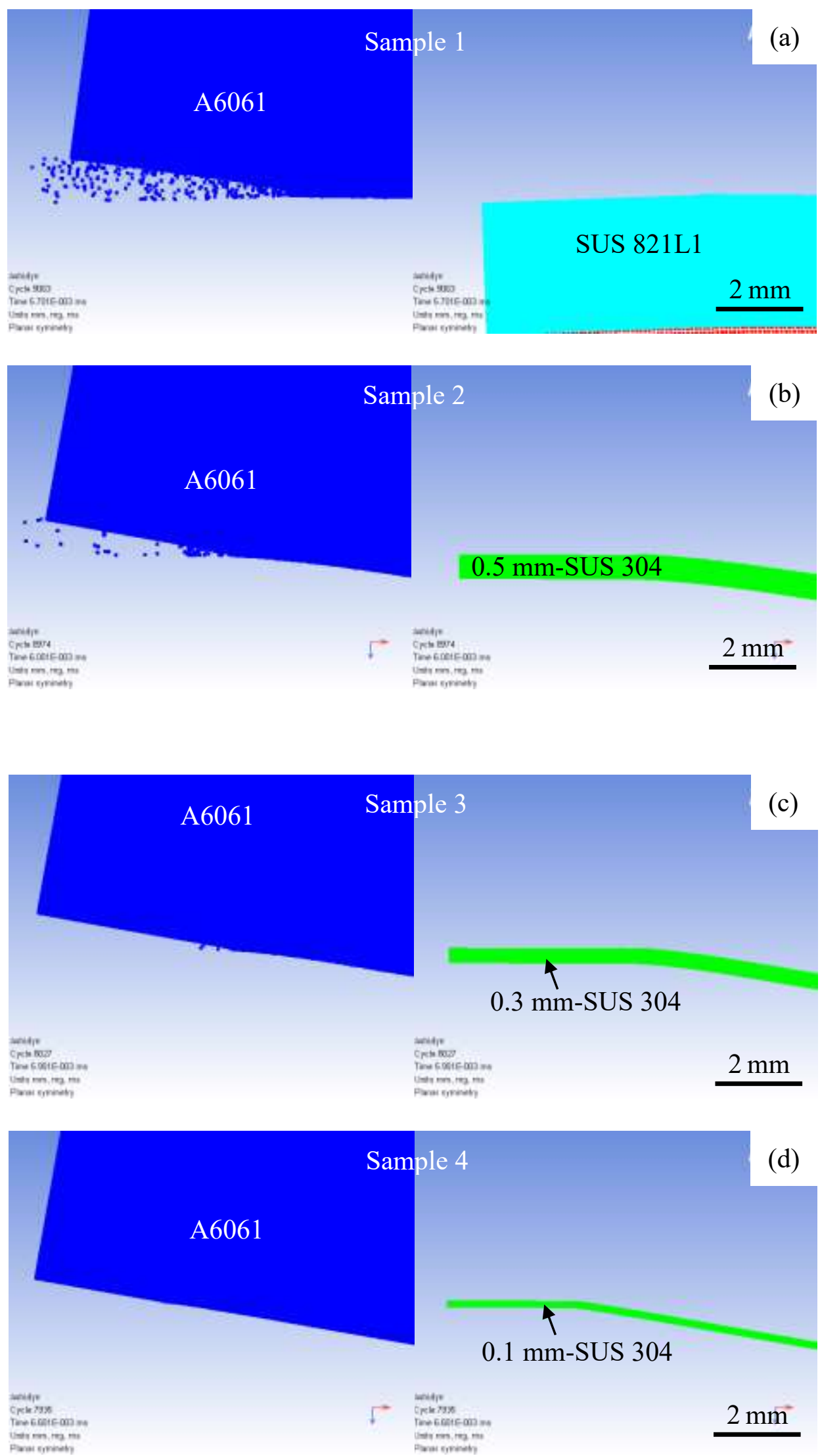

torminos

Himin m

c)

d) 

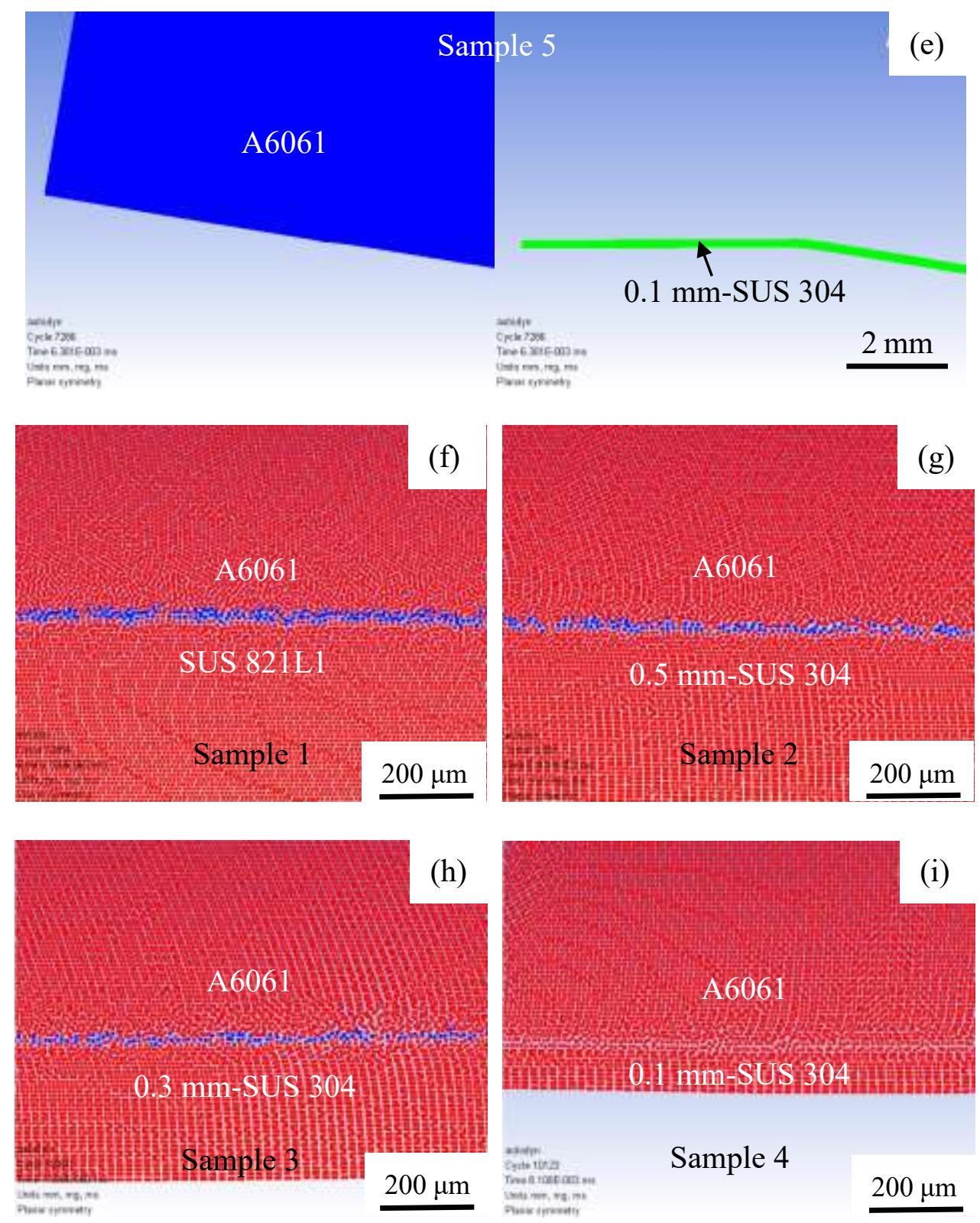

$200 \mu \mathrm{m}$

The monim

$200 \mu \mathrm{m}$
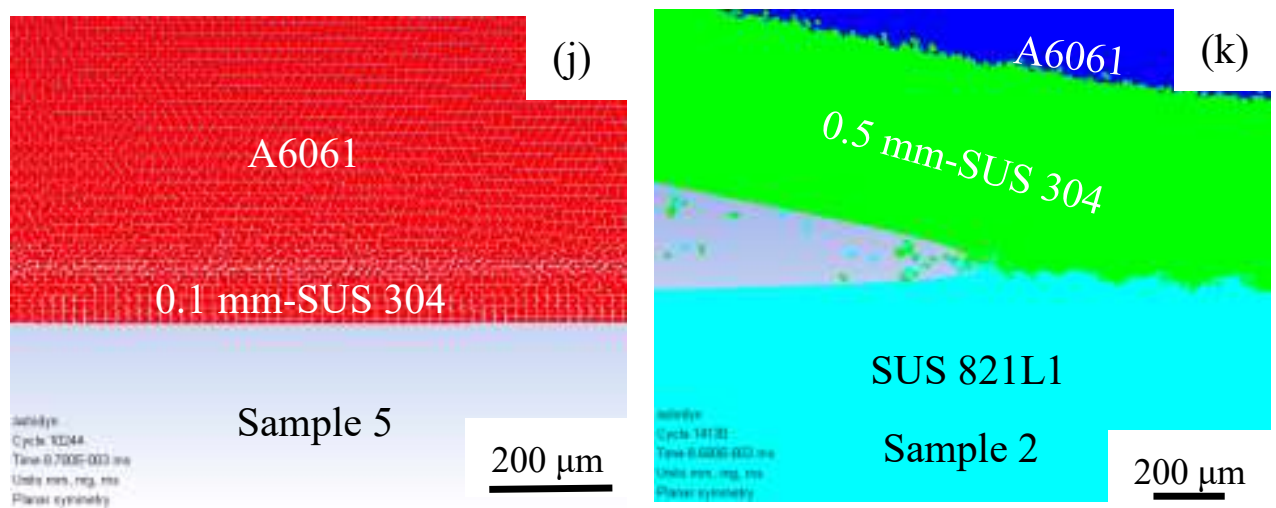

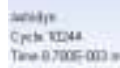

The

Sample 5

$200 \mu \mathrm{m}$

$200 \mu \mathrm{m}$ 


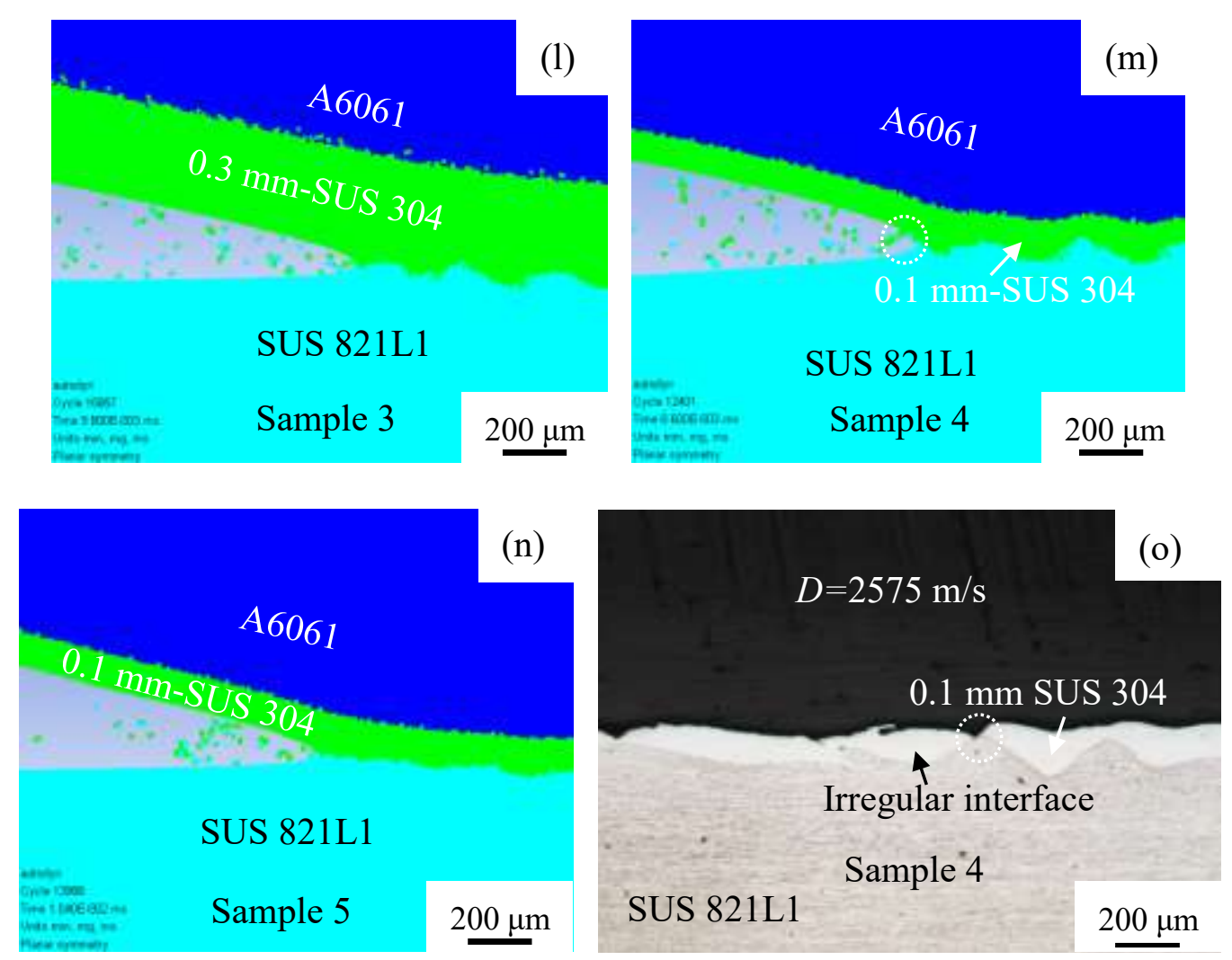

Fig. 8 Simulation of oblique collision: (a-e) the jet and interface between flyer plate and collided plate; $(\mathrm{f}-\mathrm{j})$ the melting (Von Mises stress $=0$ ) between the flyer plate and the collided plate; $(k-n)$ the jet between the interlayer and the base plate; (o) irregular interface of Sample 4.

\section{Weldability windows}

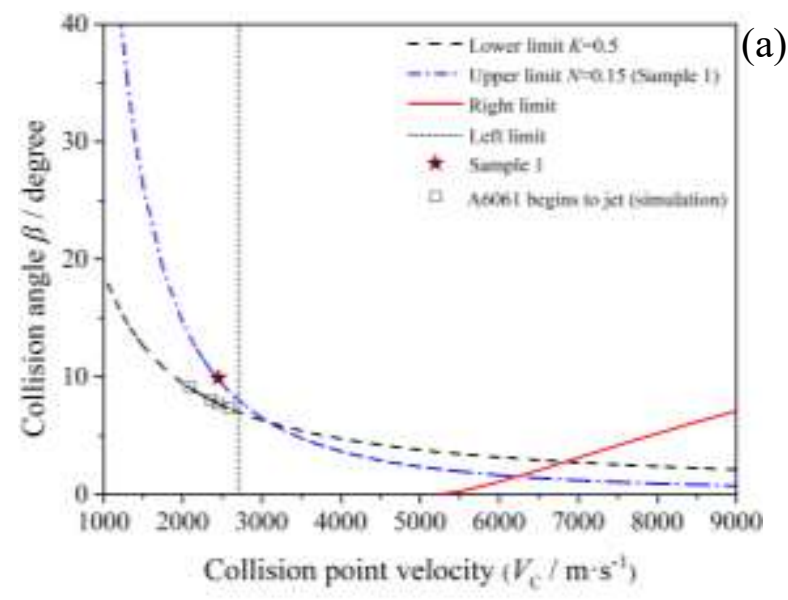



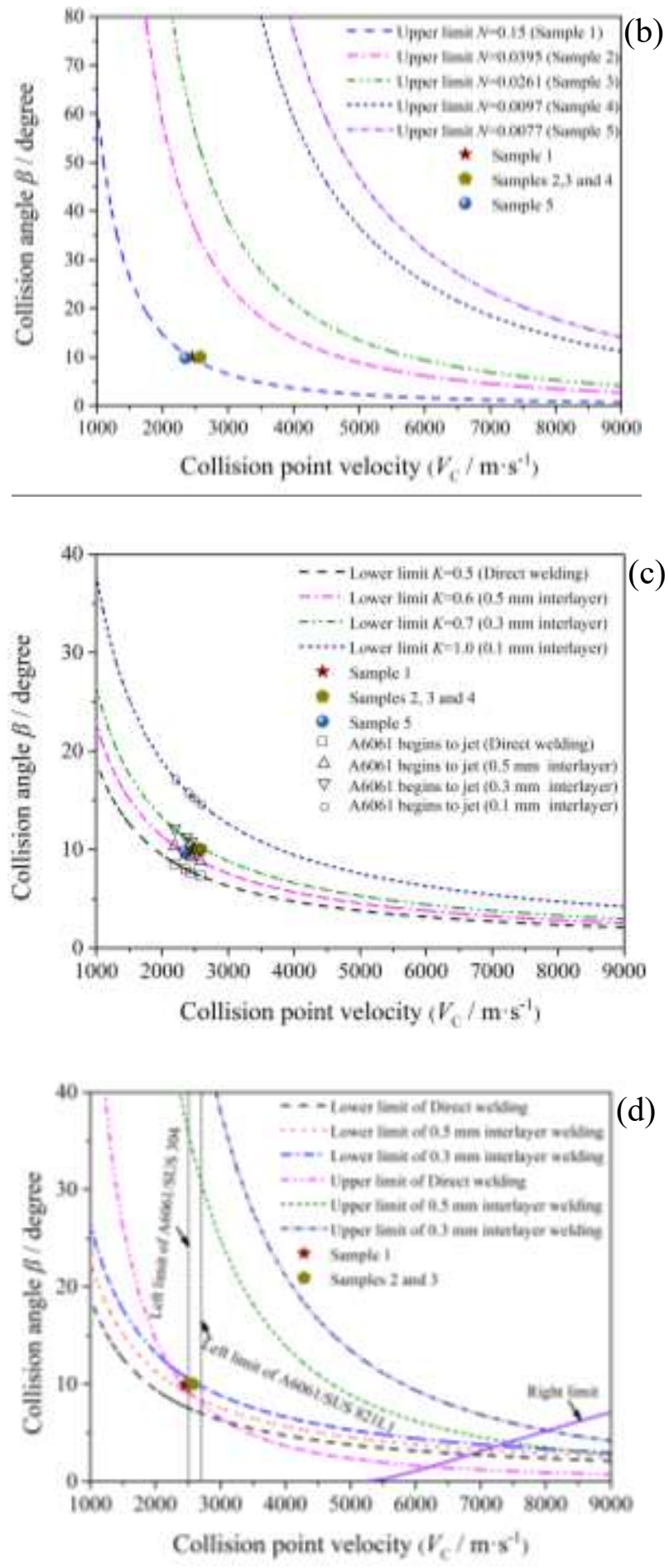


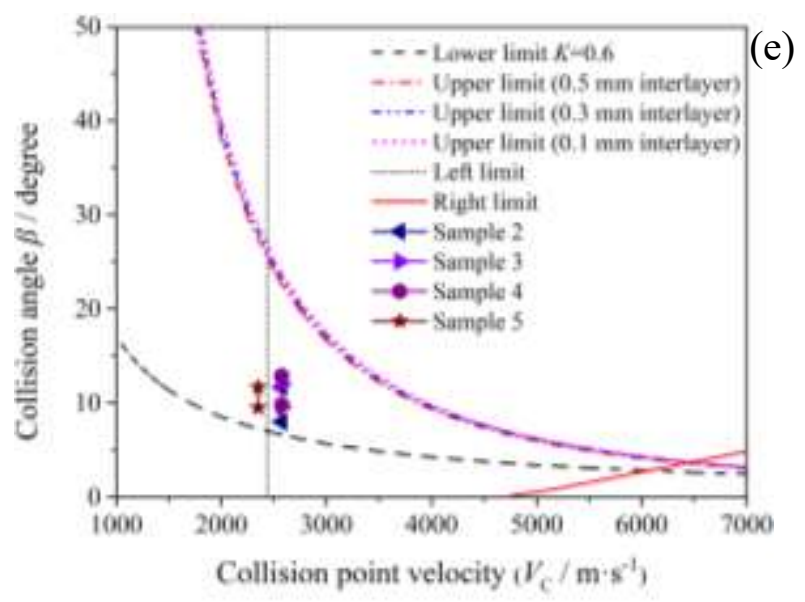

Fig. 9 Weldability window (a) direct welding of A 6061/SUS 821L1; (b) upper limits for A 6061/SUS 304 using different interlayers; (c) lower limits for A 6061/SUS 304 using different interlayers; (d) comparison of direct welding and interlayer welding; (e) window between the interlayer and the base plate.

Table 11 Properties of TP 270C, SUS 821L1 and SUS 304 9, 18, 24 .

\begin{tabular}{cccccc}
\hline & $\begin{array}{c}\text { Density } \rho \\
\left(\mathrm{kg} \cdot \mathrm{m}^{-3}\right)\end{array}$ & $\begin{array}{c}\text { Melting } \\
\text { temperature } \\
T_{\mathrm{m}}\left({ }^{\circ} \mathrm{C}\right)\end{array}$ & $\begin{array}{c}\text { Bulk sound } \\
\text { speed } C_{\mathrm{b}}\end{array}$ & $\begin{array}{c}\text { Thermal } \\
\text { conductivity } \lambda\end{array}$ & $\begin{array}{c}\text { Specific } \\
\text { heat } C_{\mathrm{p}}\end{array}$ \\
\hline A6061 & 2700 & 585 & 5240 & 167.0 & 897 \\
SUS821L1 & 7800 & 1400 & 4569 & 16.0 & 500 \\
SUS304 & 7930 & 1400 & 4569 & 16.3 & 500 \\
\hline
\end{tabular}

The weldability windows in Figs. 9 were constructed using the method in reference ${ }^{9}$ and the parameters in Table 11, and the lower limit was obtained by numerical simulations. The left limit in reference ${ }^{9}$ was used as the original data for A1100 and A6061 in the work of Cowan et al. ${ }^{25}$, whereas in this work the average value of the Reynolds number $R_{\mathrm{T}}=10.6$ was used in the left limit calculation. The right limit was used based on the method proposed by De Rosset ${ }^{26}$. Due to the low melting point of A6061, the upper limit is more strict, and $N=0.15$ was used in the upper limit calculation. For different interlayers, in the upper limit calculation, the $N$ values were determined using the ratio of the deposition energy to direct welding, and the upper limit used for SUS 304/SUS 821L1 was $N=0.037^{9}$. Fig. 9(a) shows that the welding 
parameters of Sample 1 are near the upper limit, suggesting that excessive melting caused the welding failure, in agreement with the simulation analysis. The upper limit was expanded upward by using the interlayer as shown in Fig. 9(b), so that the welding was facilitate by using the interlayers. Fig. 9(c) indicates that it was more difficult to produce the jet for thinner interlayers. The parameters of Samples 4 and 5 were below the lower limit, so that no jet was generated between the flyer plate and the interlayer during the collision process, leading to the failure of welding. Fig. 9(d) shows that although when using an interlayer, the lower limit and upper limit both shift upward, the area of the window was expanded; Due to the use of the average value of the Reynolds number, the calculated left limits were not accurate, and according to the experimental results, the welding parameters were at the left side of the left limits. It is difficult to obtain a precise estimate of the collision angle between the interlayer and the base plate. Using the method in section 4.2, a range of the collision angles can be obtained, and it was found that the parameters were in the weldability window as shown in Fig. 9(e).

\section{Conclusions}

1. For explosive welding of aluminum alloy and stainless steel, too much or too little energy deposited on the interface leads to the welding failure. The energy deposited on the interface affected the thickness of the melting layer and the bonding strength of the welding interface.

2. The interlayer led to an upward shift of the upper and lower limits of the weldability window, the area of the window expanded, and the range of the possible welding parameters expanded, facilitating welding.

3. Through theoretical and numerical simulation analysis, it was demonstrated that the air shock wave between the plates affected the movement of the interlayer during the process of explosive welding. In particular, the effect of air shock wave became 
more pronounced with thinner interlayers. The air shock wave had a negative effect on the welding results, particularly for large plates.

\section{Acknowledgment}

We sincerely thank Mr. M. Takashima and Mr. T. Akaike, Master's degree candidates, Graduate School of Science and Technology, Kumamoto University for their help and support in conducting the experiments.

\section{Declarations}

a. Funding (information that explains whether and by whom the research was supported) This study was funded by Institute of Industrial Nanomaterials, Kumamoto University. (No grant numbers)

\section{b. Conflicts of interest/Competing interests (include appropriate disclosures)}

The authors declare that they have no known competing financial interests or personal relationships that could have appeared to influence the work reported in this paper.

c. Availability of data and material (data transparency)

Not applicable.

\section{d. Code availability (software application or custom code)}

Not applicable.

e. Ethics approval (include appropriate approvals or waivers)

Not applicable.

\section{f. Consent to participate (include appropriate statements)}

All authors have approved to participate.

\section{g. Consent for publication (include appropriate statements)}

The manuscript is approved by all authors for publication. 


\section{h. Authors' contributions (optional: please review the submission guidelines from the journal}

\section{whether statements are mandatory)}

Xiang Chen did the experiments and simulations, and wrote the paper. Xiaojie Li helped to do the theoretical analysis. Daisuke Inao and Shigeru Tanaka helped to do the experiments. Kazuyuki Hokamoto provided the funding and revised the paper.

\section{References}

[1] Hatano R, Ogura T, Matsuda T, Sano T, Hirose A (2018) Relationship between intermetallic compound layer thickness with deviation and interfacial strength for dissimilar joints of aluminum alloy and stainless steel. Mat Sci Eng A-Struct 735: 361-366.

https://doi.org/10.1016/j.msea.2018.08.065

[2] Ogawa D, Kakiuchi T, Hashiba K, Uematsu Y (2019) Residual stress measurement of Al/steel dissimilar friction stir weld. Sci Technol Weld Joi 24 (8): 685-694.

https://doi.org/10.1080/13621718.2019.1588521

[3] Nguyen VN, Nguyen QM, Huang SC (2018) Microstructure and mechanical properties of butt joints between stainless steel SUS304L and aluminum alloy A6061-T6 by TIG welding. Materials 11 (7): 1136. https://doi.org/10.3390/ma11071136

[4] Liu S, Suzumura A, Ikeshoji TT, Yamazaki T (2005) Brazing of stainless steel to various aluminum alloys in air. JSME International Journal Series A Solid Mechanics and Material Engineering 48 (4): 420-425. https://doi.org/10.1299/jsmea.48.420

[5] Sherpa BB, Kumar PD, Upadhyay A, Kumar S, Agarwal A, Tyagi S (2021) Effect of explosive welding parameters on $\mathrm{Al} / \mathrm{LCS}$ interface cladded by low velocity of detonation explosive welding (LVEW) process. Int J Adv Manuf Tech 113 (11): 3303-3317. https://doi.org/10.1007/s00170021-06800-5

[6] Malakhov A, Saikov I, Denisov I (2021) Brass/Invar bimetal by explosive welding. Int J Adv Manuf Tech 114 (1): 357-364. https://doi.org/10.1007/s00170-021-06897-8

[7] Yang M, Ma H, Shen Z (2018) Study on self-restrained explosive welding with high energy efficiency. Int J Adv Manuf Tech 99 (9): 3123-3132. https://doi.org/10.1007/s00170-018-2600-y

[8] Carvalho G, Galvão I, Mendes R, Leal R, Loureiro A (2018) Explosive welding of aluminium to stainless steel. J Mater Process Tech 262: 340-349.

https://doi.org/10.1016/j.jmatprotec.2018.06.042 
[9] Chen X, Inao D, Tanaka S, Mori A, Li X, Hokamoto K (2020) Explosive welding of Al alloys and high strength duplex stainless steel by controlling energetic conditions. J Manuf Process 58: 1318-1333. https://doi.org/10.1016/j.jmapro.2020.09.037

[10] Sakai Y (2012) Success with New Products.

https://www.metalbulletin.com/events/download.ashx/document/speaker/6540/a0ID000000X0jUf MAJ/Presentation. Accessed 20 April 2021

[11] Crossland B (1982) Explosive welding of metals and its application. Clarendon Press • Oxford.

[12] Deribas A (2001) Science of explosive welding: state of art. In Impact Engineering and Application, Proceeedings of the 4th International Symposium on Impact Engineering, Chiba, A.; Tanimura, S.; Hokamoto, K., Eds. ELSEVIER. 530-531.

[13] Hokamoto K, Izuma T, Fujita M (1993) New explosive welding technique to weld. Metall Mater Trans A 24 (10): 2289-2297. https://doi.org/10.1007/BF02648602

[14] Manikandan P, Hokamoto K, Deribas AA, Raghukandan K, Tomoshige R (2006) Explosive welding of titanium/stainless steel by controlling energetic conditions. Mater Trans 47 (8): 20492055. https://doi.org/10.2320/matertrans.47.2049

[15] Tanguay V, Higgins A (2004) The channel effect: Coupling of the detonation and the precursor shock wave by precompression of the explosive. J Appl Phys 96 (9): 4894-4902. https://doi.org/10.1063/1.1787913

[16] Taylor WC, Chown JB, Morita T (1968) Measurement of rf Ionization Rates in HighTemperature Air. J Appl Phys 39 (1): 191-194. https://doi.org/10.1063/1.1655730

[17] Mahmood Y, Guo B, Chen P, Zhou Q, Bhatti A (2020) Numerical study of an interlayer effect on explosively welded joints. The International Journal of Multiphysics 14 (1): 69-80.

https://doi.org/10.21152/1750-9548.14.1.69

[18] Johnson G, Cook W (1969) Selected hugoniots: EOS. In 7th International Symposium on Ballistics. LA-4167-MS.

[19] Yang X, Ling X, Zhou J (2014) Optimization of the fatigue resistance of AISI304 stainless steel by ultrasonic impact treatment. Int J Fatigue 61: 28-38.

https://doi.org/10.1016/j.ijfatigue.2013.12.003

[20] Akram S, Jaffery SHI, Khan M, Fahad M, Mubashar A, Ali L (2018) Numerical and experimental investigation of Johnson-Cook material models for aluminum (Al 6061-T6) alloy using orthogonal machining approach. Adv Mech Eng 10 (9): 1687814018797794. 
[21] Aizawa Y, Nishiwaki J, Harada Y, Muraishi S, Kumai S (2016) Experimental and numerical analysis of the formation behavior of intermediate layers at explosive welded $\mathrm{Al} / \mathrm{Fe}$ joint interfaces. J Manuf Process 24: 100-106. https://doi.org/10.1016/j.jmapro.2016.08.002

[22] Zeng X, Li X, Li X, Mo F, Yan H (2019) Numerical study on the effect of thermal conduction on explosive welding interface. Int J Adv Manuf Tech 104 (5): 2607-2617.

https://doi.org/10.1007/s00170-019-04054-w

[23] Chen X, Li X, Wang X, Yan H, Li K, Zeng X (2019) Bonding mechanism of explosive compaction-welding sintering. J Manuf Process 46: 1-15.

https://doi.org/10.1016/j.jmapro.2019.08.018

[24] Okada N, Tadokoro Y, Tsuge S, Gonome F, Kizaki M (2017) Lean Duplex Stainless Steel for Resources Saving Society. Zairyo-to-Kankyo 66 (8): 263-267.

https://doi.org/10.3323/jcorr.66.263

[25] Cowan G, Bergmann O, Holtzman A (1971) Mechanism of bond zone wave formation in explosion-clad metals. Metall Mater Trans B 2 (11): 3145-3155.

https://doi.org/10.1007/BF02814967

[26] De Rosset (2006) Analysis of explosive bonding parameters. Mater Manuf Process 21 (6): 634-638. https://doi.org/10.1080/10426910600611136 
Figures

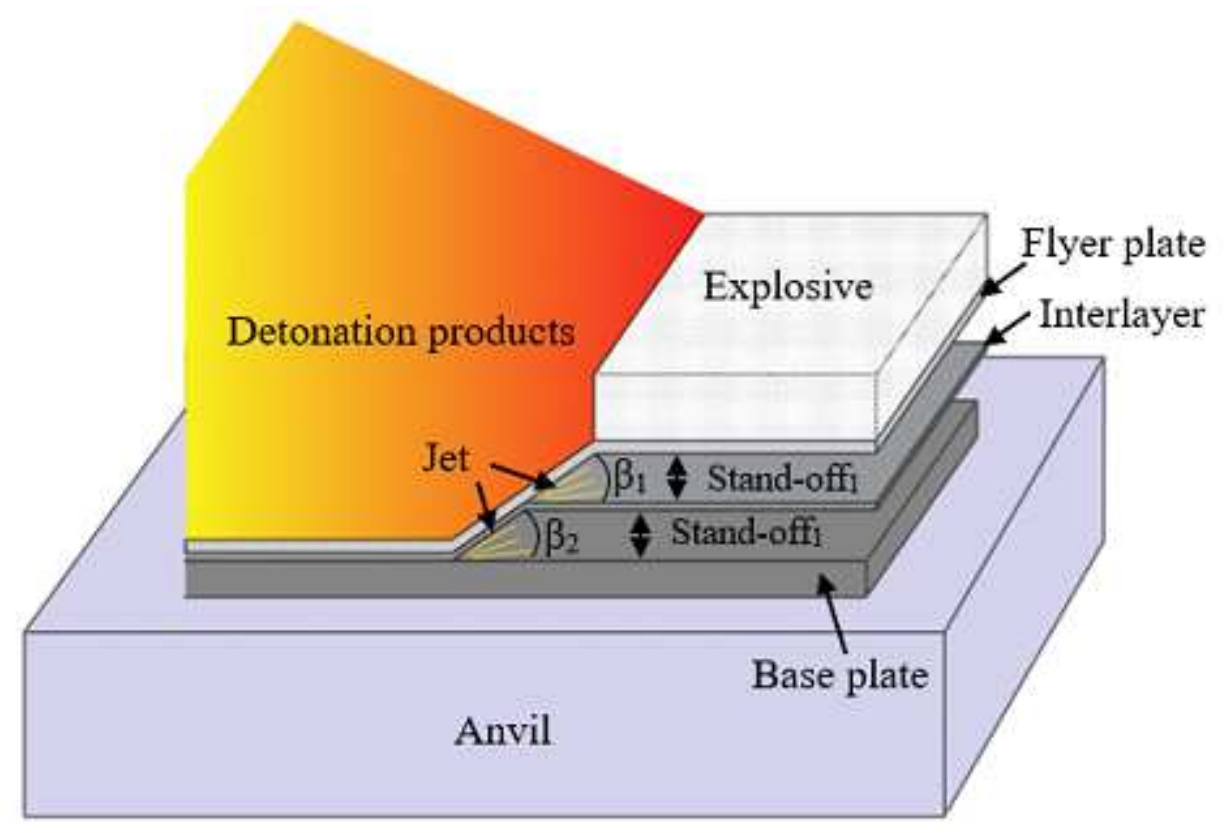

\section{Figure 1}

Schematic of explosive welding with an interlayer. 



\section{Figure 2}

Microstructure of the interface: (a, b) Sample 1; (c, d, e) Sample 2; $(f, g, h)$ Sample 3; (i, j) Sample 4; $(k, l)$ Sample 5. 

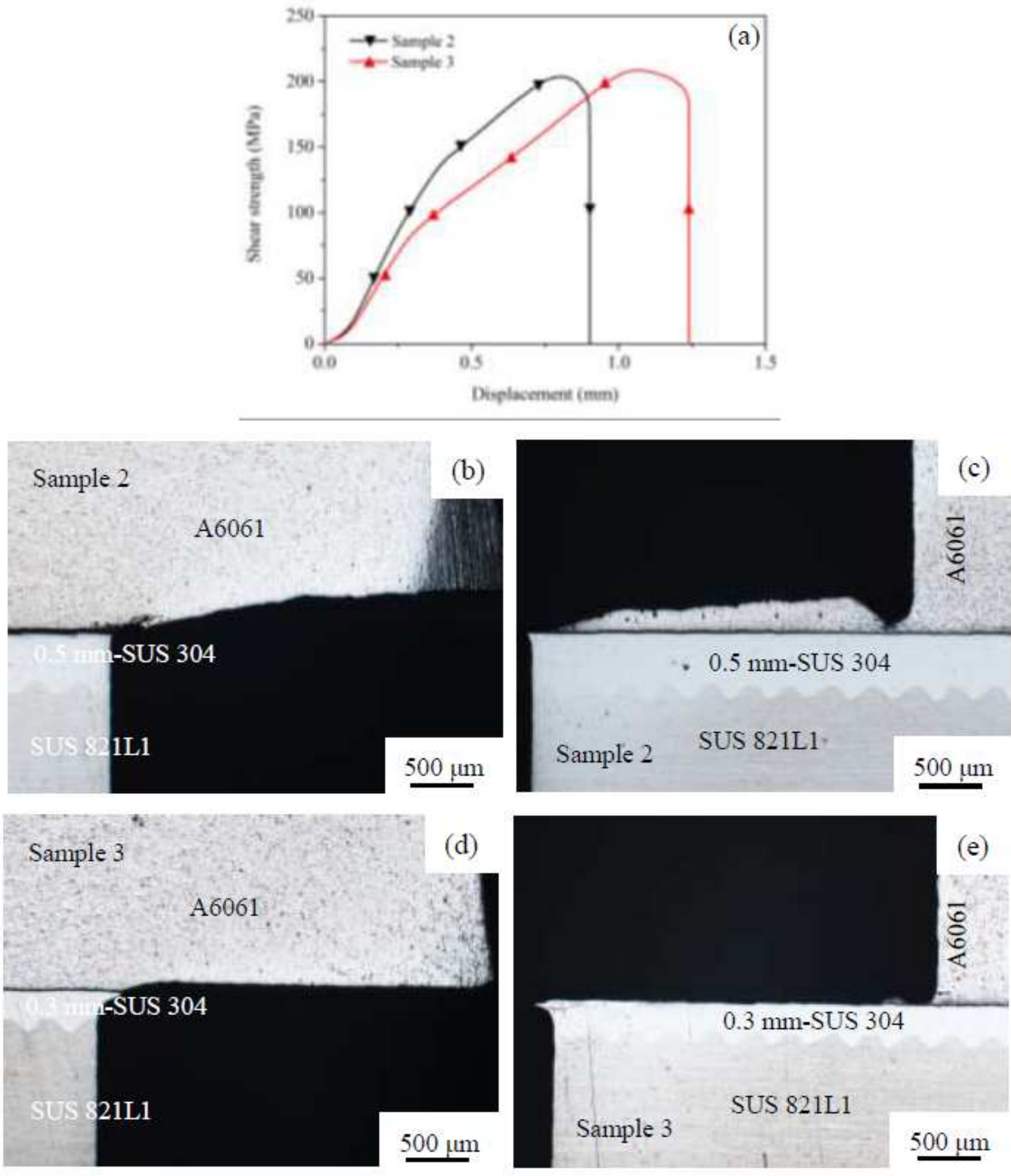

Figure 3

Tensile shear test: (a) tensile shear curve; (b) and (c) Sample 2; (d) and (e) Sample 3. 


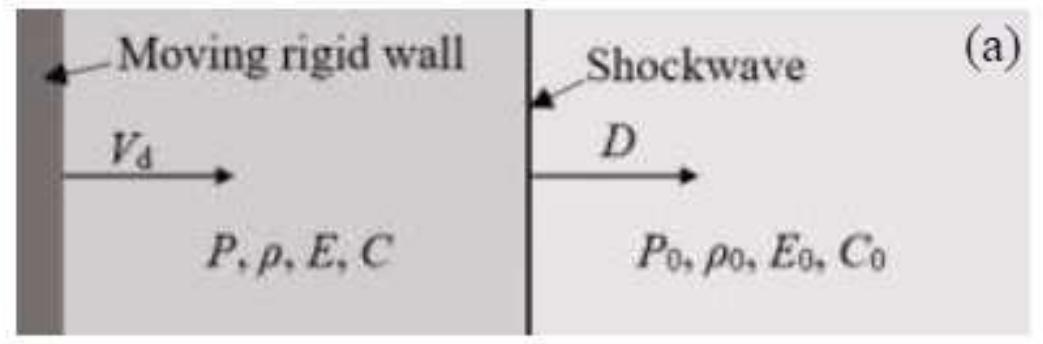

(b)

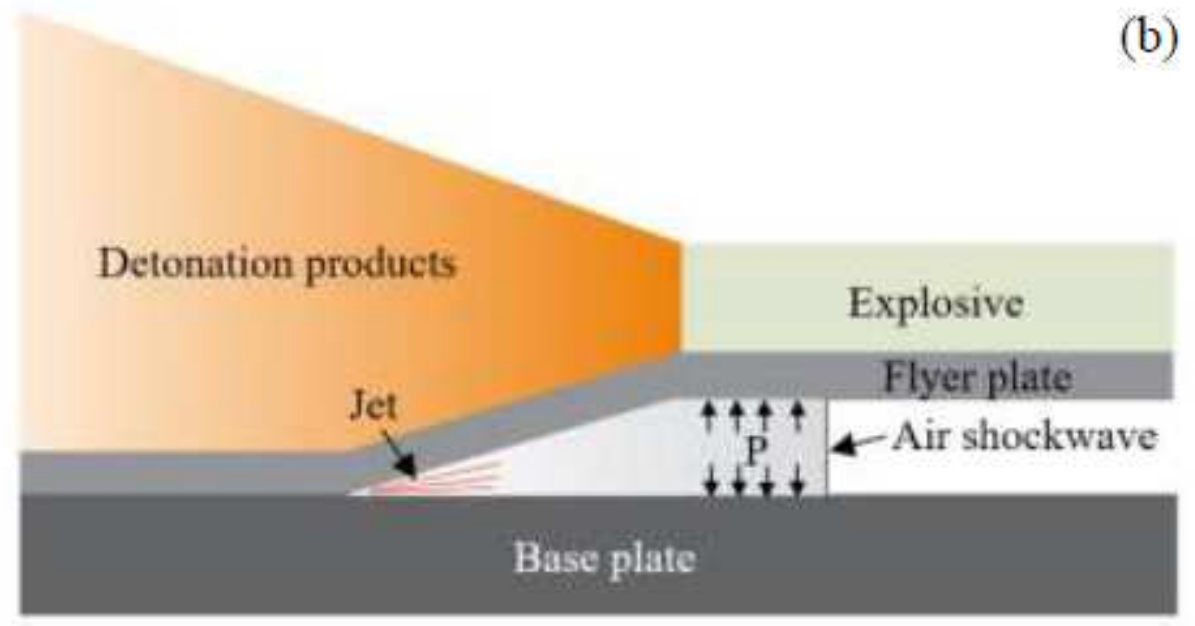

Figure 4

Schematic of the air shock wave: (a) piston model; (b) schematic of explosive welding. 
(a)
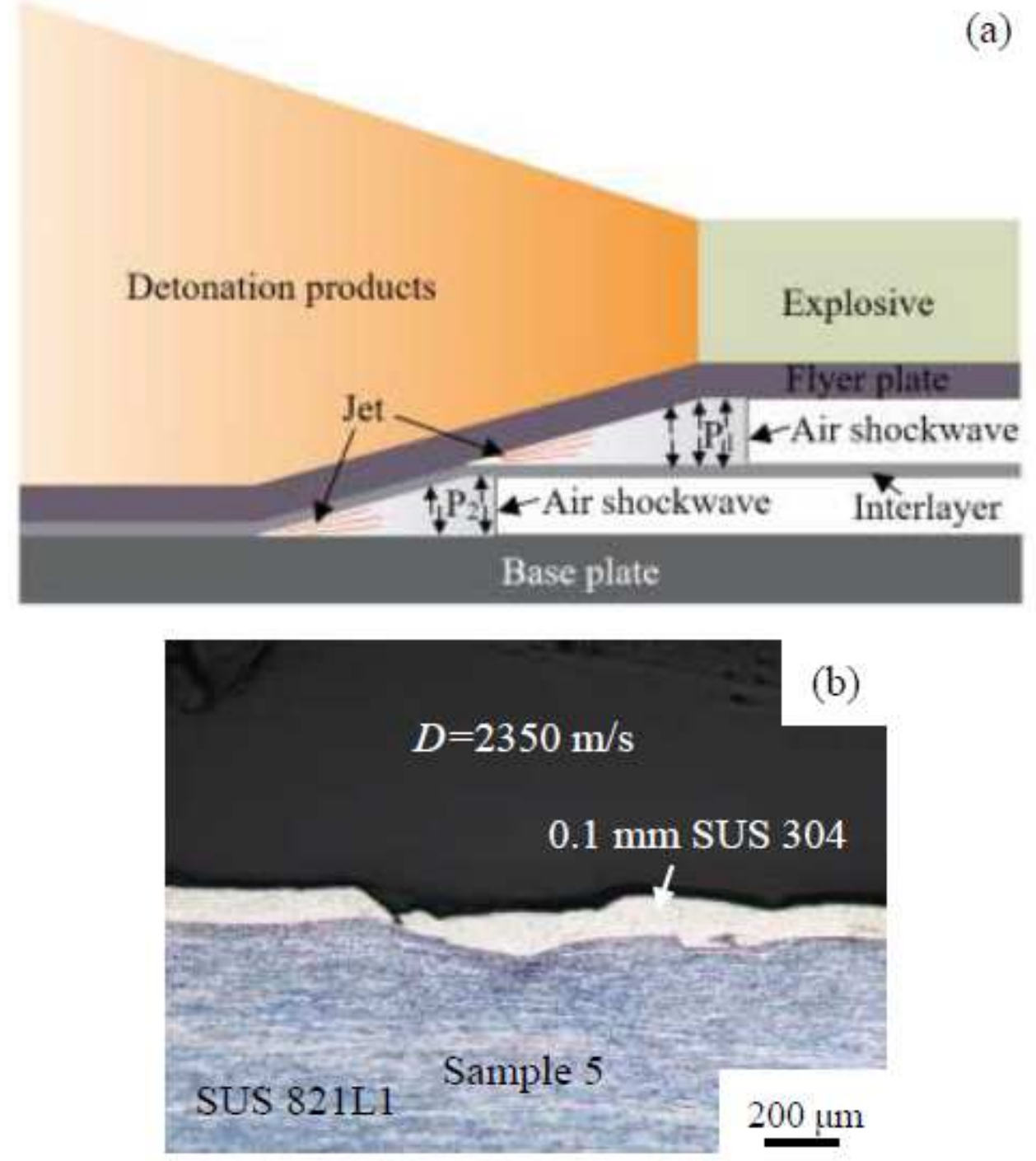

\section{Figure 5}

Schematic of the air shock wave during interlayer explosive welding. 

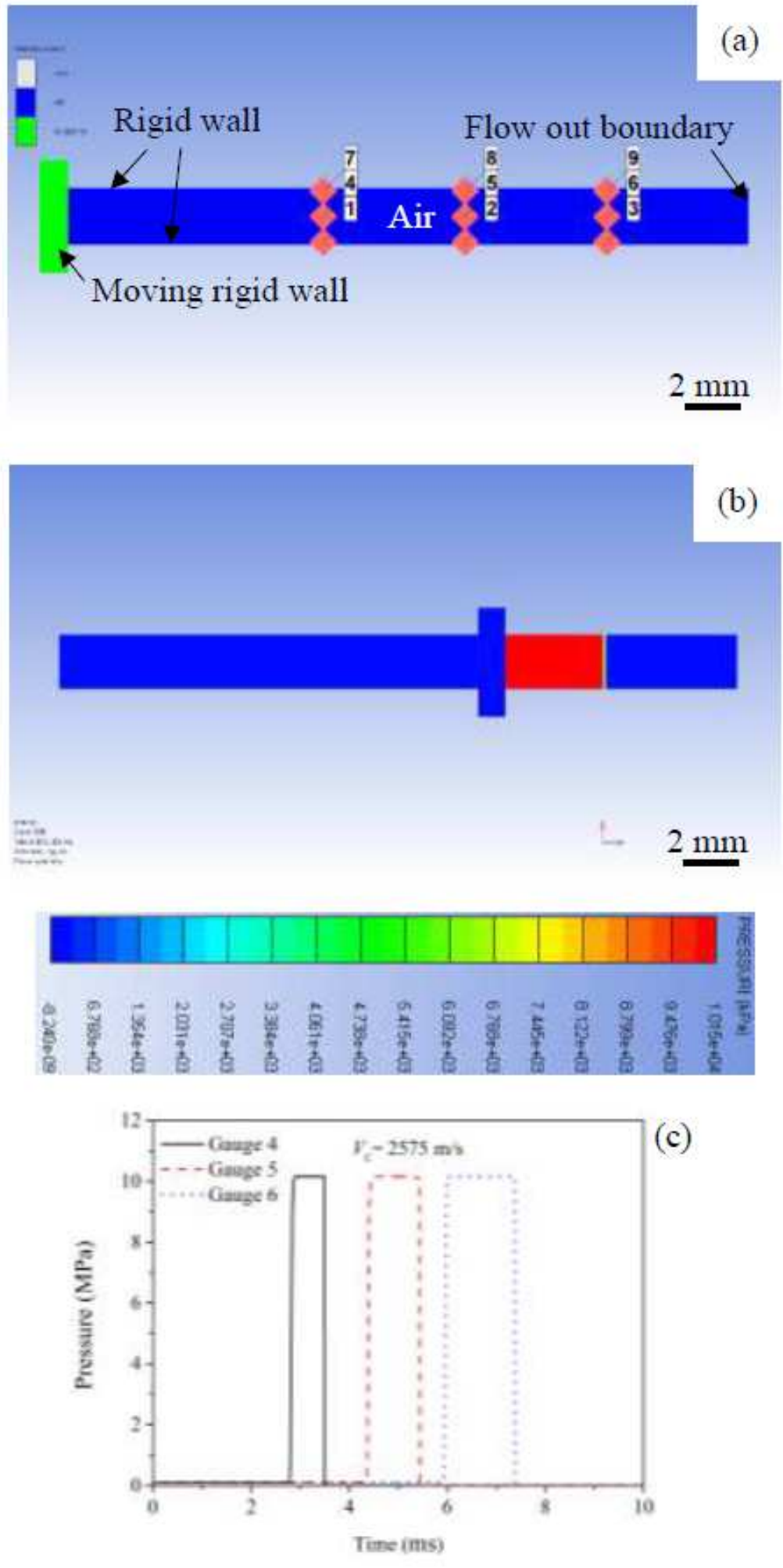

\section{Figure 6}

Simulation of the air shock wave using the piston model: (a) numerical model; (b) pressure distribution; (c) pressure curve of points 4, 5 and 6 of the oblique collision model. 

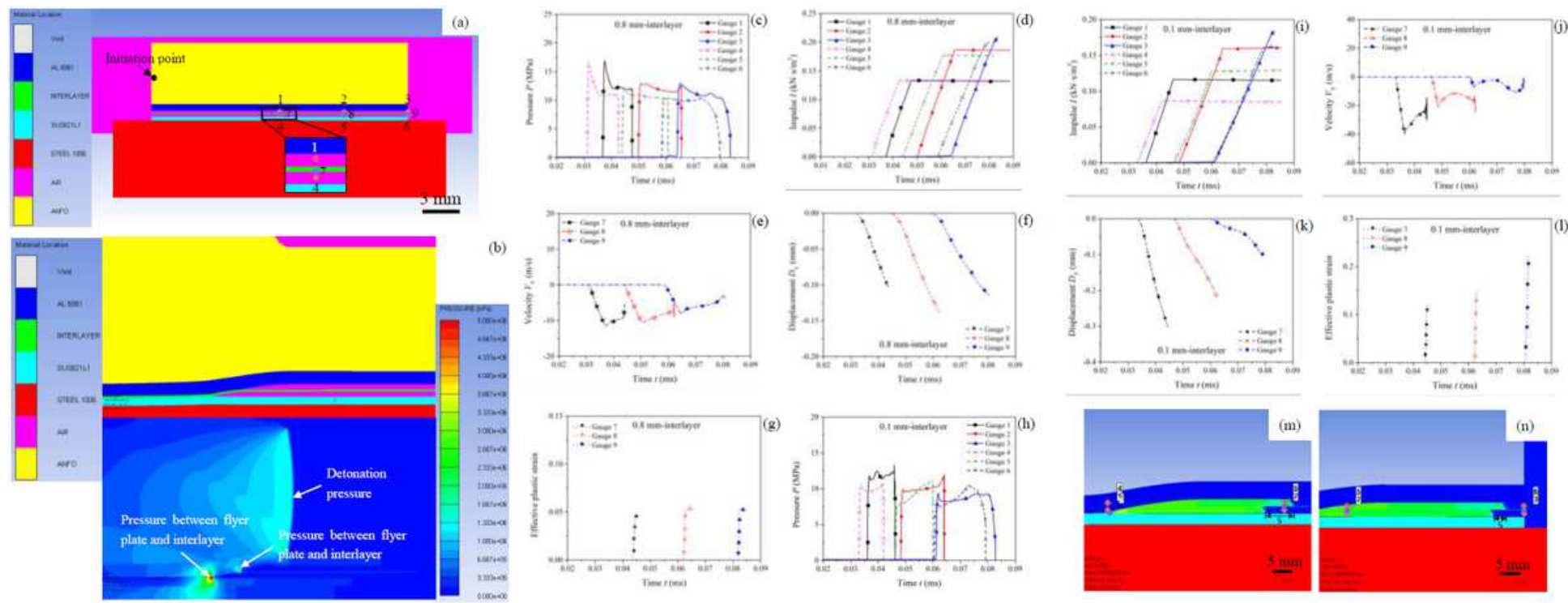

\section{Figure 7}

Simulation of the air shock wave between the plates: (a) numerical model; (b) pressure distribution of the $0.8 \mathrm{~mm}$-thick interlayer explosive welding; $(c, h)$ pressure of the air shock wave; $(d, i)$ impulse of the air shock wave $(e, j)$ interlayer's velocity under the air shock wave; $(f, k)$ interlayer's displacement under air shock; $(\mathrm{g}, \mathrm{I})$ effective plastic strain under the air shock wave; $(\mathrm{m}, \mathrm{n})$ pressure distribution of the $0.1 \mathrm{~mm}$ thick interlayer.
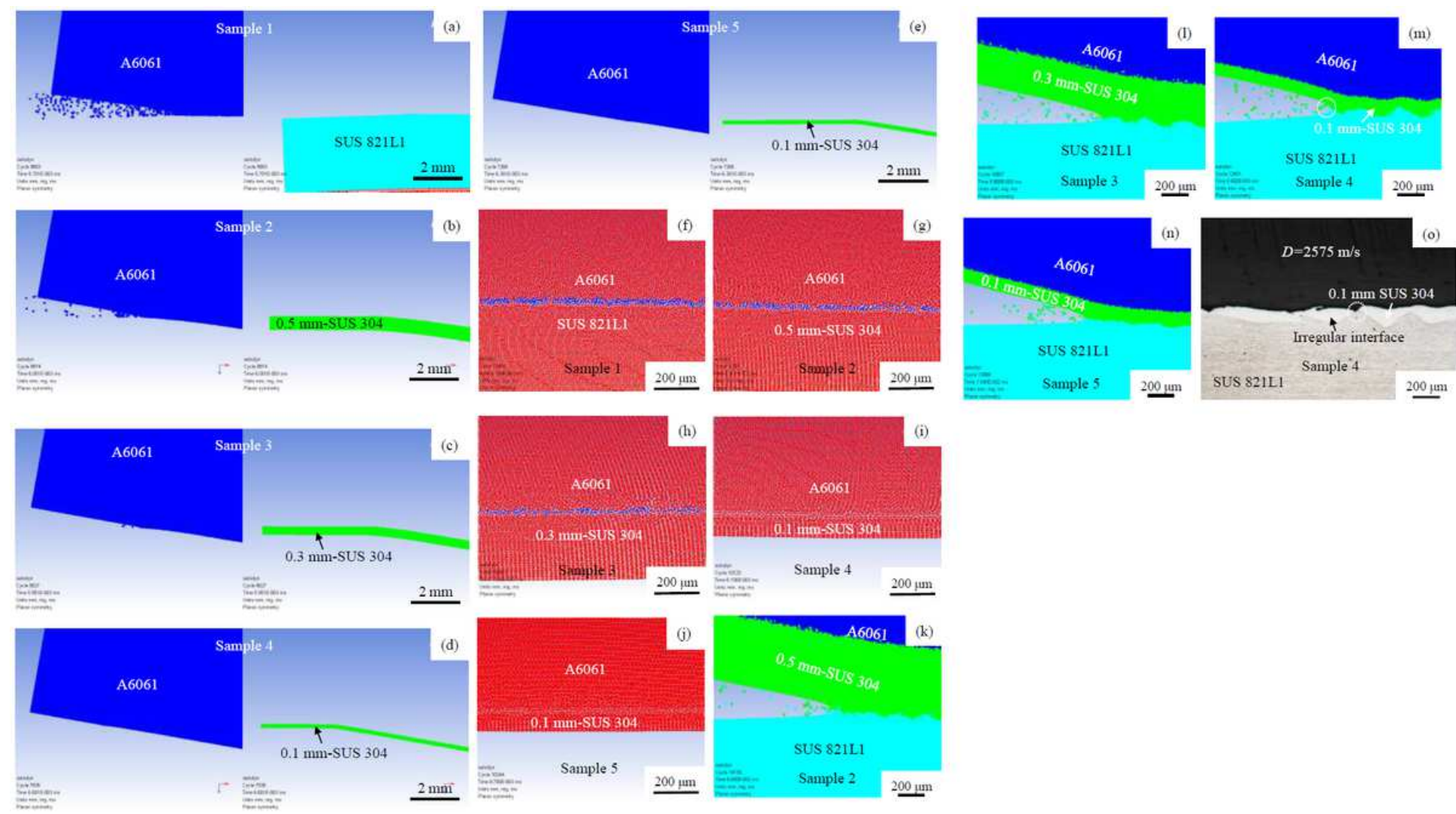

\section{Figure 8}


Simulation of oblique collision: (a-e) the jet and interface between flyer plate and collided plate; $(f-j)$ the melting (Von Mises stress $=0$ ) between the flyer plate and the collided plate; $(k-n)$ the jet between the interlayer and the base plate; (o) irregular interface of Sample 4.
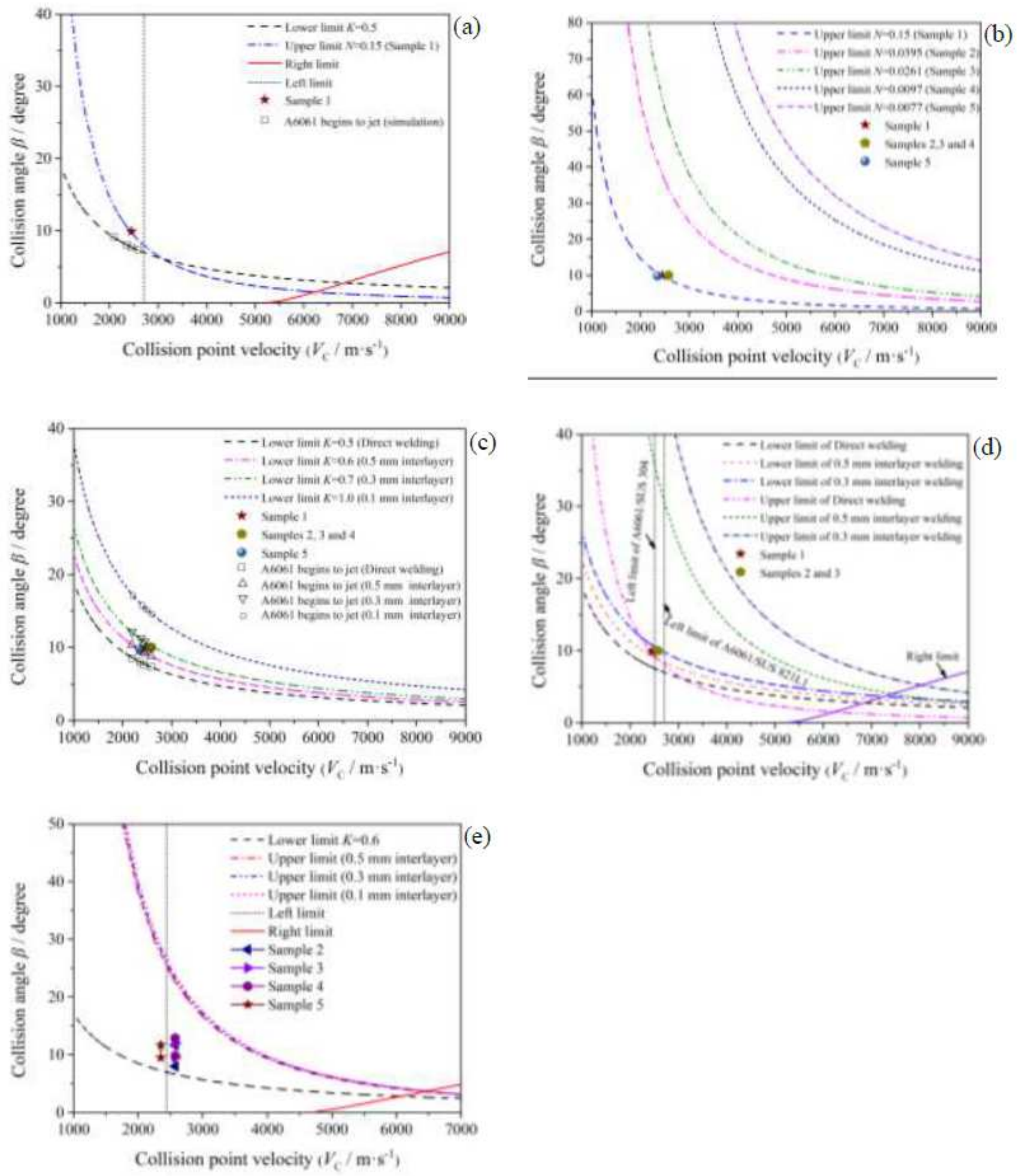

Figure 9

Weldability window (a) direct welding of A 6061/SUS 821L1; (b) upper limits for A 6061/SUS 304 using different interlayers; (c) lower limits for A 6061/SUS 304 using different interlayers; (d) comparison of 
direct welding and interlayer welding; (e) window between the interlayer and the base plate. 